Article

\title{
Analysis of the Physicochemical Characteristics of Biochar Obtained by Slow Pyrolysis of Nut Shells in a Nitrogen Atmosphere
}

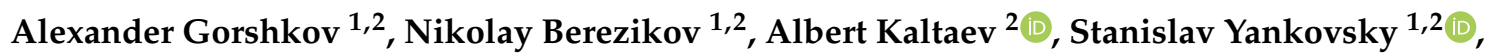 \\ Konstantin Slyusarsky ${ }^{1,2}$, Roman Tabakaev ${ }^{2,3}$ and Kirill Larionov ${ }^{1,2, *(\mathbb{D}}$ \\ 1 Laboratory of Catalysis and Conversion of Carbonaceous Materials to Obtain Useful Products, \\ Gorbachev Kuzbass State Technical University, 650000 Kemerovo, Russia; asg47@tpu.ru (A.G.); \\ nib3@tpu.ru (N.B.); jankovsky@tpu.ru (S.Y.); konstantinsv@tpu.ru (K.S.) \\ 2 School of Energy \& Power Engineering, National Research Tomsk Polytechnic University, \\ 634050 Tomsk, Russia; kaltaevalbert@gmail.com (A.K.); TabakaevRB@tpu.ru (R.T.) \\ 3 Laboratory of Catalysis and Conversion of Carbonaceous Materials to Obtain Useful Products, \\ University of Tyumen, 625003 Tyumen, Russia \\ * Correspondence: laryk070@gmail.com; Tel.: +7-3832-701-777 (ext. 1609)
}

\section{check for} updates

Citation: Gorshkov, A.; Berezikov, N.; Kaltaev, A.; Yankovsky, S.; Slyusarsky, K.; Tabakaev, R.; Larionov, K. Analysis of the Physicochemical Characteristics of Biochar Obtained by Slow Pyrolysis of Nut Shells in a Nitrogen Atmosphere. Energies 2021, 14, 8075. https://doi.org/10.3390/ en14238075

Academic Editor:

Marzena Kwapinska

Received: 15 November 2021 Accepted: 30 November 2021 Published: 2 December 2021

Publisher's Note: MDPI stays neutral with regard to jurisdictional claims in published maps and institutional affiliations.

Copyright: (c) 2021 by the authors. Licensee MDPI, Basel, Switzerland. This article is an open access article distributed under the terms and conditions of the Creative Commons Attribution (CC BY) license (https:/ / creativecommons.org/licenses/by/ $4.0 /)$.

\begin{abstract}
The process of slow pyrolysis of seven nut shell samples, in a nitrogen-purged atmosphere, has been studied, as well as characteristics of biochar obtained. The heat carrier with a temperature of $400-600{ }^{\circ} \mathrm{C}$ (with a step of $100{ }^{\circ} \mathrm{C}$ ) was supplied indirectly using a double-walled reactor. The heating rate was $60^{\circ} \mathrm{C} / \mathrm{min}$. At increased temperature of the heating medium, a decrease in the amount of the resulting carbon residue averaged $6.2 \mathrm{wt} \%$. The release of non-condensable combustible gas-phase compounds $\mathrm{CO}, \mathrm{CH}_{4}$, and $\mathrm{H}_{2}$, with maximum concentrations of $12.7,14.0$, and $0.7 \mathrm{vol} \%$, respectively, was registered. The features of the obtained biochar sample conversions were studied using thermal analysis in inert (nitrogen) and oxidative (air) mediums at $10^{\circ} \mathrm{C} / \mathrm{min}$ heating rate. Kinetic analysis was performed using Coats-Redfern method. Thermal analysis showed that the main weight loss $(\Delta \mathrm{m}=32.8-43.0 \mathrm{wt} \%)$ occurs at temperatures ranging between $290{ }^{\circ} \mathrm{C}$ and $400{ }^{\circ} \mathrm{C}$, which is due to cellulose decomposition. The maximum carbon content and, hence, heat value were obtained for biochars made from macadamia nut and walnut shells. An increased degree of coalification of the biochar samples affected their reactivity and, in particular, caused an increase in the initial temperature of intense oxidation (on average, by $73^{\circ} \mathrm{C}$ ). While technical and elemental composition of nut shell samples studied were quite similar, the morphology of obtained biochar was different. The morphology of particles was also observed to change as the heating medium temperature increased, which was expressed in the increased inhomogeneity of particle surface. The activation energy values, for biochar conversion in an inert medium, were found to vary in the range of $10-35 \mathrm{~kJ} / \mathrm{mol}$ and, in an oxidative medium $-50-80 \mathrm{~kJ} / \mathrm{mol}$. According to literature data, these values were characteristic for lignin fibers decomposition and oxidation, respectively.
\end{abstract}

Keywords: nut shell; pyrolysis; biochar; heating medium temperature; gas-phase products; heat of combustion; elemental composition

\section{Introduction}

The pyrolysis is a useful technology for the valorization of biomass of different origins [1,2]. Biochar obtained could be used as a feedstock for production of supercapacitors, batteries, and as fuel, catalyst, or adsorbent [1]. Nut shells are a widespread biomass in many regions worldwide [3], which makes them a suitable feedstock for this process. The biochar, obtained via pyrolysis of nut shells, is known to be a suitable carbon-neutral fuel [3] and a feedstock for many other applications. A common issue, in this area, is varying properties of different biomass feedstocks, making obtaining products with stable characteristics problematic. 
The walnut shell biochar, produced via pyrolysis in a muffle furnace at $700{ }^{\circ} \mathrm{C}$ for $2 \mathrm{~h}$ at $5{ }^{\circ} \mathrm{C} / \mathrm{min}$ heating rate, was found to be a very strong adsorbent for metolachlor removal [4]. The chichá-do-cerrado shell biochar, produced in a stainless reactor at $500{ }^{\circ} \mathrm{C}$ with $1 \mathrm{~h}$ exposure at $10^{\circ} \mathrm{C} / \mathrm{min}$ heating rate, showed good adsorption properties after activation by $\mathrm{KOH}$ [5]. The pine nut shell, obtained in a screw reactor at $650{ }^{\circ} \mathrm{C}$ with $10 \mathrm{~min}$ exposure and impregnated with $\mathrm{H} \beta / \mathrm{Ni}-\mathrm{V}$ catalyst, exhibited excellent performance for the bio-oil hydrodeoxygenation [6]. In addition, a good catalytic activity towards oxygen reduction was observed for olive and pistachio nut shell biochars, obtained at $600{ }^{\circ} \mathrm{C}$ with $30 \mathrm{~min}$ exposure time and activated in $\mathrm{CO}_{2}$ at $800{ }^{\circ} \mathrm{C}$ for $45 \mathrm{~min}$ [7].

Kinetic data on the pyrolysis of shells of different nuts is widely presented in literature [3,8-10]. However, these data significantly vary depending on type of the feedstock and the experimental method used. For example, the activation energy values of the pyrolysis of walnut, hazelnut, peanut, and pistachio shells, given in [8], varied within the range of 30-150 kJ/mol, while in [9], this range was 150-300 kJ/mol. The sensitivity analysis [11] revealed that the variation in activation energy has the most significant effect on the pyrolysis rate making such uncertainty critical for practical calculations. In [3], it was reported that the kinetics of thermal degradation and oxidation of biochar pellets, consisting of coffee husk, palm nut shells, and fibers could be determined according to the superposition principal using kinetic parameters of individual components. Thus, the experiment appears to be the most reliable method to study the pyrolysis of nut shells.

The effect of pyrolysis temperature on the adsorption properties of the pine nut shell biochars, obtained using a screw-type continuous pyrolysis reactor with 15 min exposure in the temperature range of $300-700{ }^{\circ} \mathrm{C}$, was described in [12]. The most developed pore structure of the biochar was observed at $500{ }^{\circ} \mathrm{C}$. Similar research was carried out into pine nut shells [13]: the maximum specific surface area was obtained at high temperature and pressure of the process. The opposite results were reported in [14], where the pyrolysis temperature increased from $400{ }^{\circ} \mathrm{C}$ to $600{ }^{\circ} \mathrm{C}$ (in a nitrogen atmosphere and with $2 \mathrm{~h}$ exposure) decreased the specific surface area of almond and nut shell biochars. Similar results were reported in [15] for the peanut shell biochar, obtained by $\mathrm{H}_{3} \mathrm{PO}_{4}$ treatment and pyrolysis at $650{ }^{\circ} \mathrm{C}$ in a nitrogen atmosphere, with $2 \mathrm{~h}$ exposure in case of Acid Yellow 36 removal. Good adsorption properties for heavy metals $(\mathrm{Cd}, \mathrm{Hg}, \mathrm{Pb})$ were reported in [16] for shea and groundnut shell biochars obtained by pyrolysis at $350{ }^{\circ} \mathrm{C}$ and $700{ }^{\circ} \mathrm{C}$. Despite a large number of studies, the majority of them are focused on one of two types of nut shells, which hinders the comparison of different solutions for processing nut shells of different origin.

This study reports the results of the parametric study into the effect of pyrolysis temperature on the characteristics of biochars derived from seven different nut shell samples.

\section{Materials and Methods}

\subsection{Feedstock}

The shells of different nuts (pine nuts, hazelnuts, walnuts, macadamia nuts, almonds, peanuts, pistachio nuts) were used as a feedstock. The samples were preliminarily ground in a mill and fractioned using sieves, with a mesh size of less than $1 \mathrm{~mm}$.

\subsection{Pyrolysis}

Figure 1 presents a schematic diagram of the experimental setup for nut shell pyrolysis. A $30 \mathrm{~g}$ sample of the fractioned nut shell was placed into a cylindrical reactor, with $145 \mathrm{~mL}$ (height $-115 \mathrm{~mm}$, diameter-40 mm) operating in a batch mode. About $70-80 \%$ of the reactor volume was filled depending on the bulk density of the nut shell samples. After that, heat was supplied to the reactor bottom (indirectly) by preheating the air, using a thermally regulated air heater LHS 61L PREMIUM (LEISTER, Kaegiswil, Switzerland) that allows high air flow with up to $16 \mathrm{~kW}$ heating power (maximum heating temperature $650^{\circ} \mathrm{C}$ ). Air was supplied to the heater using a high-pressure fan AIRPACK (LEISTER, Kaegiswil, Switzerland). The temperature of the heating medium attained $400-600{ }^{\circ} \mathrm{C}$ 
(with a step of $100{ }^{\circ} \mathrm{C}$ ). The temperature inside the reactor was continuously monitored using an installed thermocouple $\mathrm{T}$ connected to an electronic recorder Termodat-25E6 (Termodat, Permian, Russia). During the pyrolysis, the reactor chamber was continuously purged with nitrogen, and the flow rate attained $2 \mathrm{~L} / \mathrm{min}$.

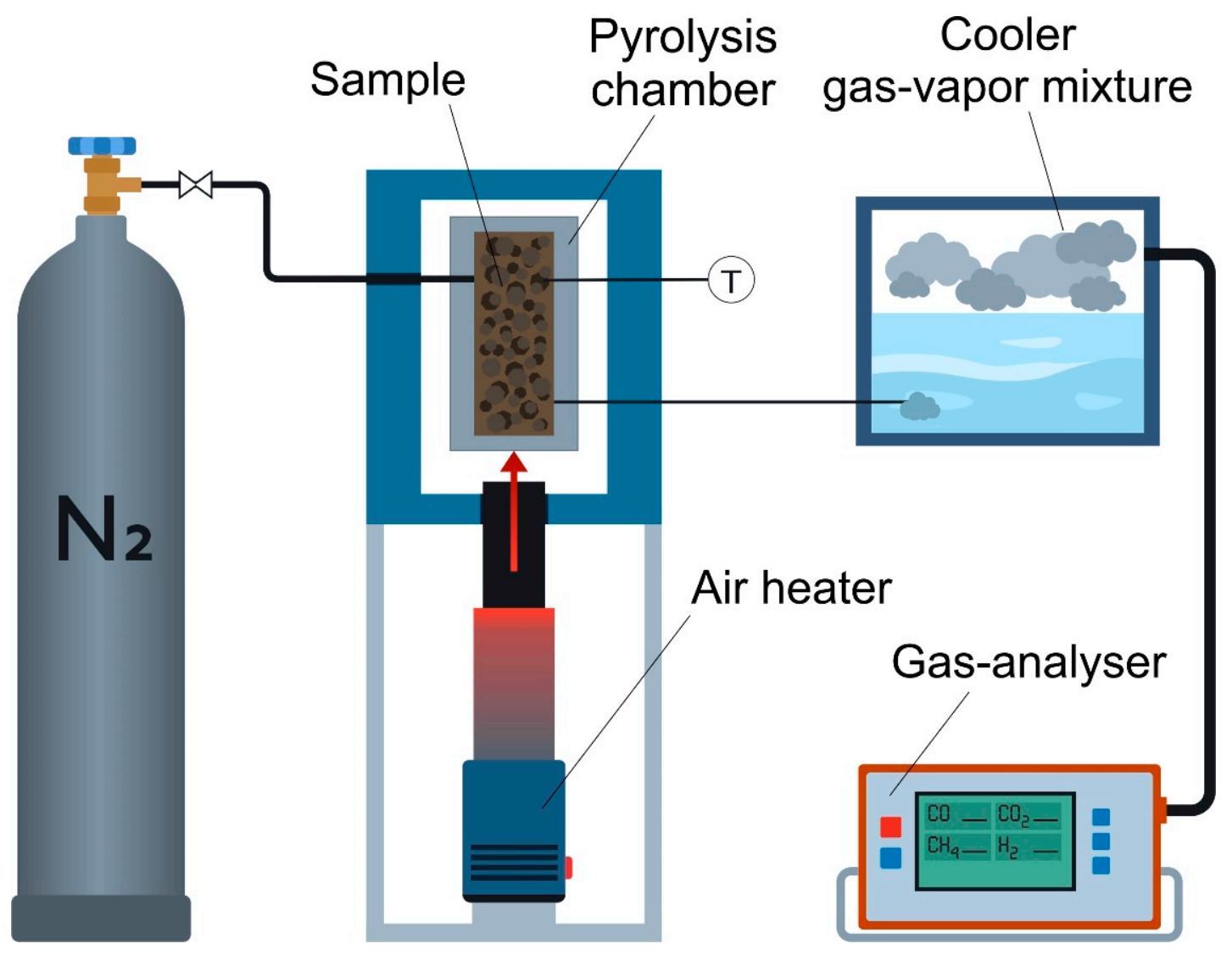

Figure 1. Schematic diagram of the experimental setup for pyrolysis of nut shell biomass.

Vapor gases formed during the pyrolysis were cooled, by bubbling in water, in a vessel with $100 \mathrm{~mL}$ volume (height $-80 \mathrm{~mm}$, diameter $-40 \mathrm{~mm}$ ). The amount of water in the vessel was $60 \mathrm{~mL}$. Non-condensable gas-phase pyrolysis products were investigated using an in-line gas analyzer Test-203 (BONER, Novosibirsk, Russia). Concentration measurement ranges of the gas analyzer used were: $\mathrm{O}_{2}-0-21 \mathrm{vol} \%, \mathrm{CO}-0-50 \mathrm{vol} \%$, $\mathrm{CO}_{2}-0-100 \mathrm{vol} \%, \mathrm{H}_{2}-0-40 \mathrm{vol} \%$ and $\mathrm{CH}_{4}-0-50 \mathrm{vol} \%$. The relative measurement error was- $\pm 5 \%$. Frequency of measurements-3 s.

The first stage of the experimental study involved heating the reactor and the nut shell sample (indirectly) to the specified temperature $\left(\mathrm{T}_{\mathrm{g}}=400-600^{\circ} \mathrm{C}\right)$. The heating rate was $60^{\circ} \mathrm{C} / \mathrm{min}$, which is characteristic of slow pyrolysis $[17,18]$. This stage is accompanied by the evaporation of external and bound moisture, and the subsequent sublimation of volatile compounds (cellulose, hemicellulose, and lignin) [19]. When the specified $\mathrm{T}_{\mathrm{g}}$ was attained, the temperature was maintained constant in the reactor until the completion of the pyrolysis (stage II). The pyrolysis was considered complete in the absence of gas-phase compounds $\mathrm{CO}, \mathrm{CO}_{2}, \mathrm{CH}_{4}$, and $\mathrm{H}_{2}$, which were quantitatively recorded using the in-line gas analyzer. Next, the reactor was cooled (stage III) to exclude spontaneous combustion of the biochar produced during the biomass pyrolysis. The heating and cooling rate of the reactor was controlled by adjusting the frequency of the alternating current of the air blower.

For each of the samples and each of the specified heating medium temperatures $\left(\mathrm{T}_{\mathrm{g}}=400-600^{\circ} \mathrm{C}\right)$, the experiment was performed five times. 


\subsection{Characterization of Materials}

Prior to analytical studies, the initial and resulting carbon samples were ground and fractionated, using sieves with a mesh size of less than $200 \mu \mathrm{m}$.

The characteristics (moisture, ash, volatile matter content, low calorific value LHV, iodine number) were determined according to standard ISO methods: ISO 589:2008 «Hard coal. Determination of total moisture»; ISO 1171:2010 «Solid mineral fuels. Determination of ash»; ISO 562:2010 «Hard coal and coke. Determination of volatile matter»; ISO 1928:2009 «Solid mineral fuel. Determination of gross calorific value and calculation of net calorific value»; ASTM D4607 «Activated carbon. Standard test method for determination of iodine number». The content of carbon, hydrogen, nitrogen, and sulfur was determined using a Flash 2000 CHNS analyzer (Thermo Fisher Scientific, Waltham, MA, USA). The morphological characteristics were studied using a scanning electron microscope SEM JSM-6000C (JEOL, Tokyo, Japan).

Thermal decomposition (in inert and oxidizing atmosphere) of the samples was performed using a simultaneous thermal analyzer STA 449 F3 Jupiter (Netzsch, Selb, Germany). The analysis was carried out at a heating rate of $10^{\circ} \mathrm{C} / \mathrm{min}$ up to $1000{ }^{\circ} \mathrm{C}$ in oxidizing (air) and inert (argon) atmosphere. The gas flow rate attained $150 \mathrm{~mL} / \mathrm{min}$. The sample weight was $15 \mathrm{mg}( \pm 0.1 \mathrm{mg})$. All the experiments were carried out under atmospheric pressure.

\subsection{Kinetic Analysis}

The activation energy $\left(E_{a}\right)$ was chosen as the characteristic kinetic parameter. The activation energy of the thermal conversion was determined by the Coats-Redfern method [8]. This method is based on the Equation (1):

$$
\operatorname{Ln}\left[-\frac{\operatorname{Ln}(1-\alpha)}{T^{2}}\right]=\operatorname{Ln}\left[\frac{\mathrm{AR}}{\beta}\right]-\frac{E_{a}}{R T}
$$

here, $\alpha$ is conversion, which was varied in range from 0 to 1 ; $T$ is temperature, $K ; R$ is universal gas constant, $\mathrm{J} /(\mathrm{mol} \mathrm{K})$; A frequency factor, $\min ^{-1} ; \mathrm{E}_{\mathrm{a}}$ activation energy, $\mathrm{J} / \mathrm{mol}$; $\beta$ heating rate, $\mathrm{K} / \mathrm{min}$.

The solution of Equation (1) and the determination of the main parameters were carried out, using TG analysis results by building the dependence of the left side of the equation on $1 / \mathrm{T}$. The obtained dependence was approximately linear via Equation (2).

$$
\operatorname{Ln}\left[-\frac{\operatorname{Ln}(1-\alpha)}{T^{2}}\right]=C_{1}+\frac{C_{2}}{T}
$$

The value of the activation energy was found by multiplying the coefficient $C_{2}$ by the universal gas constant.

\section{Results and Discussion}

\subsection{Nut Shell Characteristics}

Table 1 summarizes the characteristics and elemental composition of the nut shell samples.

Generally, the nut shell samples exhibit similar characteristics and elemental composition. This type of biomass is characterized by a low ash content $\mathrm{A}^{\mathrm{d}}=0.4-1.1 \mathrm{wt} \%$ (except for the peanut shell sample $\mathrm{A}^{\mathrm{d}}=3.4 \mathrm{wt} \%$ [20]) and a high content of volatile compounds $\mathrm{V}^{\mathrm{r}}=66.4-72.7 \mathrm{wt} \%$ and oxygen $\mathrm{O}^{\mathrm{d}}=40.3-46.7 \mathrm{wt} \%$, which is characteristic of the biomass [21]. In turn, the LHV value (17.5-20.3 MJ $/ \mathrm{kg}$ ) is comparable not only with other types of the biomass but also with low-grade coals (Lignite/brown coal or Sub-bituminous coal) [22]. 
Table 1. Physicochemical characteristics of the nut shell samples.

\begin{tabular}{|c|c|c|c|c|c|c|c|c|c|c|}
\hline \multirow{3}{*}{ Sample } & \multirow{3}{*}{ Symbol } & \multicolumn{4}{|c|}{ Characteristics } & \multicolumn{5}{|c|}{ Elemental Composition * } \\
\hline & & $\mathbf{W}^{r}$ & $A^{d}$ & $\mathbf{V}^{\mathbf{r}}$ & LHV & $C^{d}$ & $H^{d}$ & $\mathrm{~N}^{\mathrm{d}}$ & $S^{d}$ & $O^{d}$ \\
\hline & & & $w t \%$ & & $\mathrm{MJ} / \mathrm{kg}$ & \multicolumn{5}{|c|}{ wt $\%$} \\
\hline Pine nut & Pine & 5.2 & 0.4 & 67.9 & 20.3 & 51.4 & 6.7 & 1.2 & - & 40.3 \\
\hline Hazelnut & $\mathrm{H}$ & 8.8 & 0.9 & 66.4 & 18.9 & 50.8 & 6.2 & 0.2 & - & 41.9 \\
\hline Walnut & $\mathrm{W}$ & 3.7 & 1.1 & 69.3 & 17.8 & 48.4 & 5.9 & 0.5 & - & 44.1 \\
\hline Macadamia & M & 3.1 & 0.3 & 66.9 & 19.5 & 51.9 & 5,4 & 0.2 & - & 42.0 \\
\hline Almond & A & 3.9 & 0.7 & 72.7 & 18.5 & 50.3 & 5.7 & 0.2 & - & 43.1 \\
\hline Peanut & Pean & 4.5 & 3.4 & 67.4 & 18.3 & 47.6 & 6.1 & 1.4 & - & 41.5 \\
\hline Pistachio & Pist & 3.7 & 0.5 & 70.3 & 17.5 & 46.9 & 5.8 & 0.1 & - & 46.7 \\
\hline
\end{tabular}

r_as-received basis, ${ }^{\mathrm{d}}$ - dry basis, ${ }^{*}$ - prior to the analysis, the sample was dried to constant weight at $105^{\circ} \mathrm{C}$.

According to [23], these characteristics are appropriate for pyrolysis. For example, a low-ash feedstock, used for pyrolysis, eliminates ash aggregation and maintains a constant rate of heat transfer. Additionally, inorganic minerals in the ash composition can negatively affect the mechanisms of biomass pyrolysis [24].

Figure 2 presents images of the initial samples obtained using a scanning electron microscope.

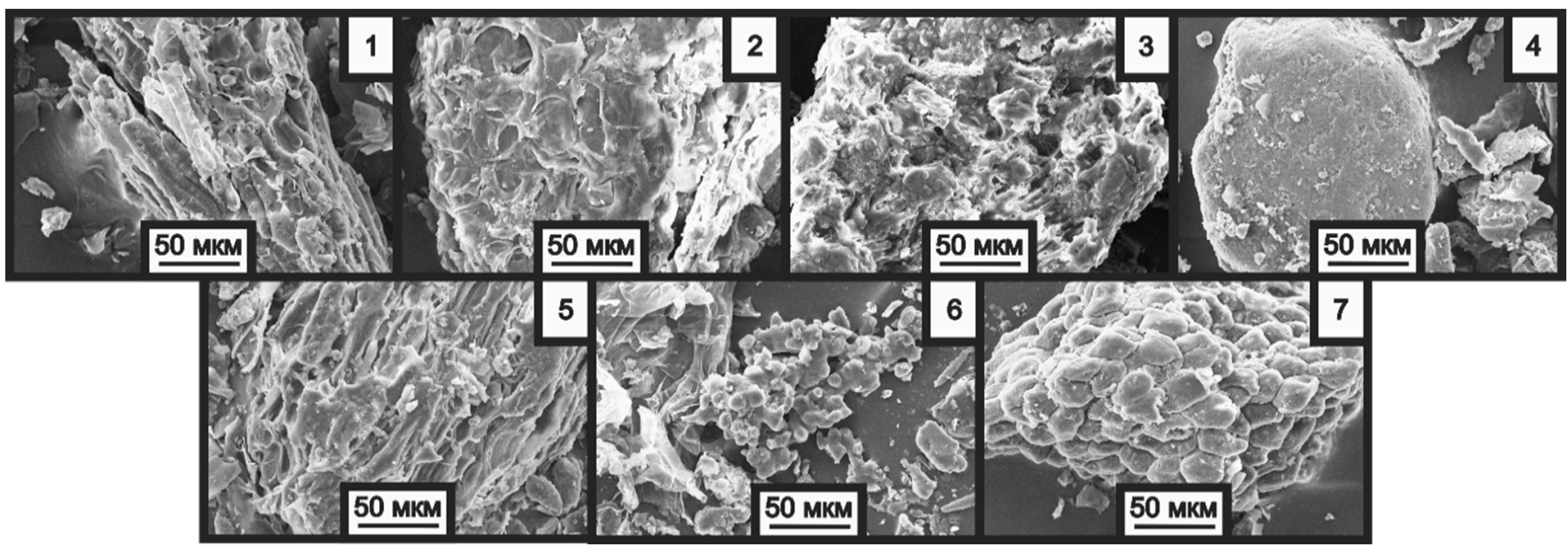

Figure 2. SEM images of nut shell samples: 1-Pine, 2-Hazelnut, 3-Walnut, 4-Macadamia, 5-Almond, 6-Peanut, 7-Pistachio. Particle size is less than $200 \mu \mathrm{m}(\times 500)$.

The data obtained by scanning electron microscopy show different structure and morphology of the nut shell samples. This can be clearly observed for the peanut and pistachio shell samples, which exhibit an inhomogeneous shape and surface of the particles. In other samples, the particles are spherical and cylindrical, which is characteristic of most vegetable materials.

Figure 3 presents the results of the thermal analysis of the nut shell samples in an inert atmosphere. Table 2 presents the calculated values of the characteristics and activation energy values $\left(E_{a}\right)$ of thermal conversion process. 


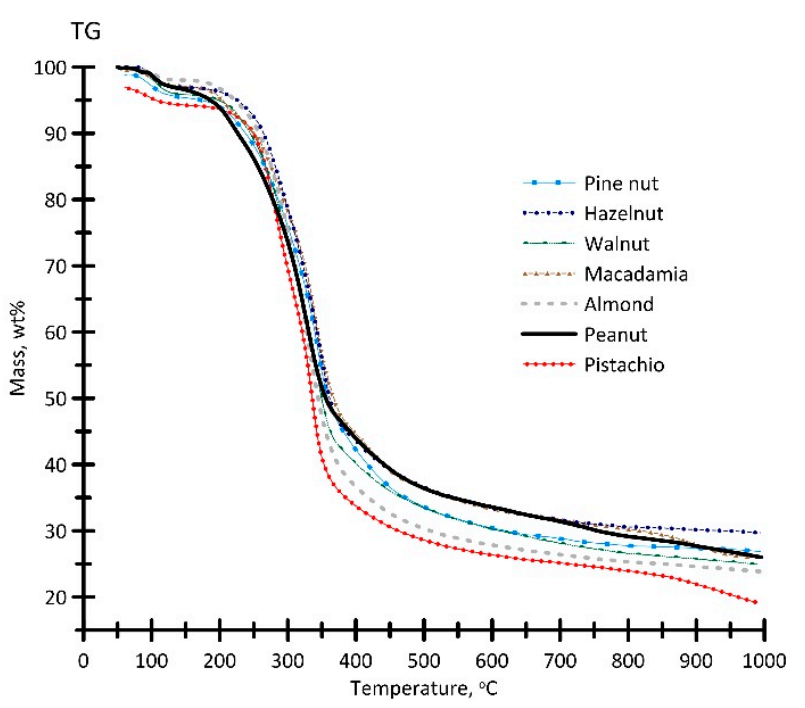

(a)

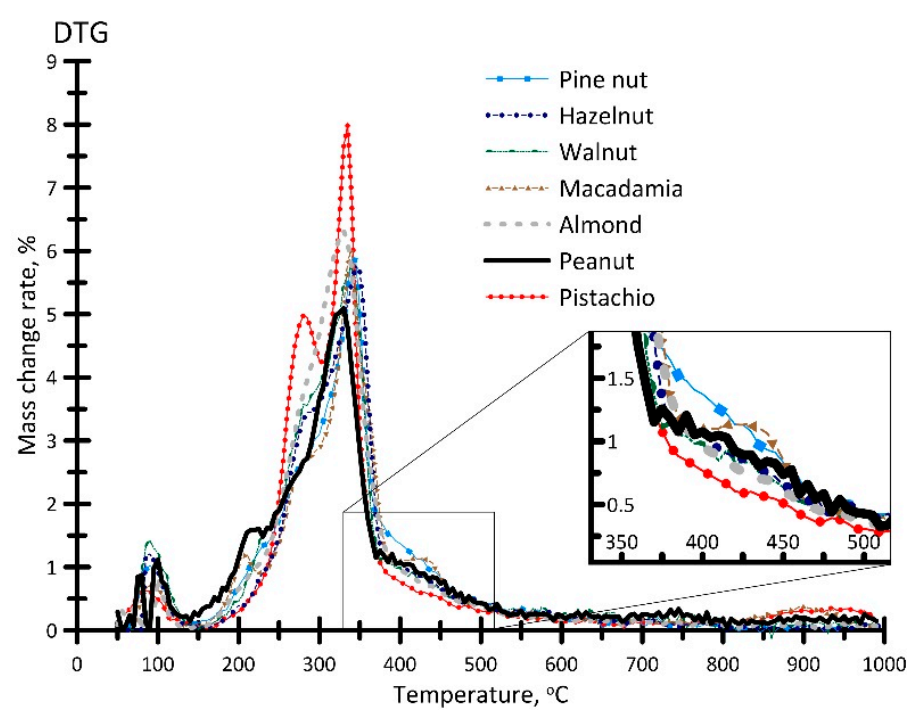

(b)

Figure 3. TG (a) and DTG (b) profiles for the process of thermal decomposition of the samples in an inert atmosphere. Argon flow rate $-150 \mathrm{~mL} / \mathrm{min}$, heating rate $-10^{\circ} \mathrm{C} / \mathrm{min}$, sample weight $\approx 15 \mathrm{mg}$.

Table 2. Thermal conversion parameters.

\begin{tabular}{cccccc}
\hline & $\mathbf{T}_{\mathbf{d}},{ }^{\circ} \mathbf{C}$ & $\mathbf{T}_{\mathbf{f}}{ }^{\circ} \mathbf{C}$ & $\mathbf{T}_{\mathbf{m a x}}$ & $\mathbf{w}_{\mathbf{m a x}}$ & $\mathbf{E}_{\mathbf{a}}$ \\
\hline & & ${ }^{\circ} \mathbf{C}$ & & $\mathbf{w t} \mathbf{\%} / \mathbf{m i n}$ & $\mathbf{~ k J / m o l}$ \\
\hline Pine nut & 250 & 420 & 340 & 5.9 & 20.1 \\
Hazelnut & 275 & 440 & 340 & 5.7 & 23.1 \\
Walnut & 250 & 400 & 345 & 5.8 & 18.4 \\
Macadamia & 275 & 430 & 340 & 6.0 & 19.2 \\
Almond & 250 & 400 & 330 & 6.4 & 12.4 \\
Peanut & 250 & 415 & 330 & 5.1 & 17.6 \\
Pistachio & 250 & 390 & 335 & 7.9 & 12.4 \\
\hline
\end{tabular}

The TG and DTG profiles, presented in Figure 3, are similar in pattern due to similar characteristics and elemental composition of the samples (Table 1). For all the samples presented, the change in weight amounted to $68-77 \mathrm{wt} \%$ (Figure 3a), which is in good correlation with the above values of moisture content and the yield of volatile compounds (Table 1). The initial temperature of the intense thermal decomposition $\mathrm{T}_{\mathrm{d}}$ of the samples attained $250-275{ }^{\circ} \mathrm{C}$.

As can be seen in Figure 3b, the DTG profiles are bimodal in shape. The first maximum on the DTG curves can be attributed to the moisture removal (up to $5.4 \mathrm{wt} \%$ at $130{ }^{\circ} \mathrm{C}$ ), and the second one (at $180-570{ }^{\circ} \mathrm{C}$ ) is due to sublimation and removal of volatile compounds. It should be noted that, for the pistachio, peanut, and macadamia shell samples, the DTG curves are slightly different, which is associated with the formation of additional reflections at different temperatures. In general, the process of thermal conversion of the samples, in this temperature range, can be due to the decomposition of the main structural components of the biomass: hemicellulose $\left(200-370^{\circ} \mathrm{C}\right)$, cellulose $\left(275-400{ }^{\circ} \mathrm{C}\right)$ and, to a lesser extent, lignin (above $400{ }^{\circ} \mathrm{C}$ ) [25]. Thus, the main peak $\left(290-400{ }^{\circ} \mathrm{C}\right)$ is mainly due to the pyrolysis of cellulose $(\Delta \mathrm{m}=8.7-11.9 \mathrm{wt} \%)$, and the shoulder peak $\left(210-275^{\circ} \mathrm{C}\right)$ can be attributed to thermal decomposition of hemicellulose $(\Delta \mathrm{m}=8.7-11.9 \mathrm{wt} \%)$. Residual decomposition of lignin at $400-570{ }^{\circ} \mathrm{C}$ was about $6.9-11.1 \mathrm{wt} \%$. The obtained residue consisted of carbon and ash.

The maximum values of the rate of the weight change $\mathrm{w}_{\max }=6.4$ and $7.9 \mathrm{wt} \% / \mathrm{min}$ are found for the peanut and pistachio shell samples, respectively. For other samples, $\mathrm{w}_{\max }$ 
amounted to $5.1-5.8 \mathrm{wt} \% / \mathrm{min}$. In this case, $\mathrm{T}_{\max }$ (corresponding to $\mathrm{w}_{\max }$ ) ranges from $330{ }^{\circ} \mathrm{C}$ to $345^{\circ} \mathrm{C}$.

The minimum activation energy value was $12.4 \mathrm{~kJ} / \mathrm{mol}$ for pistachio and almond samples. The highest value was obtained for the samples of hazelnuts and pine nuts, which were 23.1 and $20.1 \mathrm{~kJ} / \mathrm{mol}$, respectively. Such low values may indicate the physical nature of this process (for example, evaporation of the poorly bound extractives) or the overlapping of several simultaneously occurring reactions.

The DSC data show that thermal conversion of the samples at $220-650{ }^{\circ} \mathrm{C}$ proceeds in an endothermic mode. The maximum value of the integrand area of the DSC curve was found for the peanut and almond shell samples.

\subsection{Biochar Yields}

Figure 4 illustrates changes in the biochar yield, depending on the heating medium temperature $\left(\mathrm{T}_{\mathrm{g}}=400-600^{\circ} \mathrm{C}\right)$.

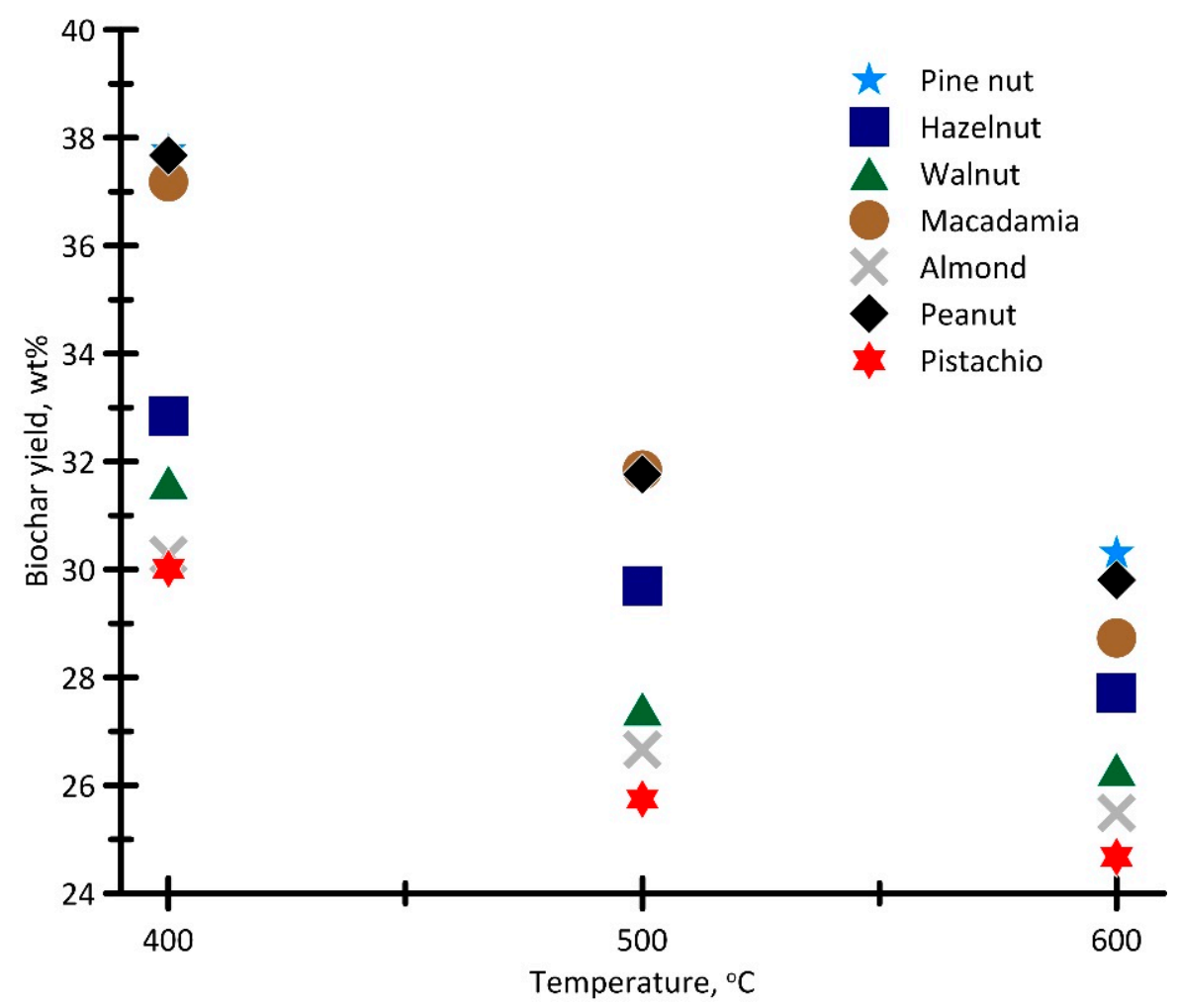

Figure 4. Dependence of changes in the biochar yield on the heating medium temperature.

Despite similar characteristics of the nut shell samples (Table 1), the maximum biochar yield in the considered temperature range was observed for the macadamia, peanut, and pine nut shell samples. For these samples, the biochar yield at $\mathrm{T}_{\mathrm{g}}=400{ }^{\circ} \mathrm{C}$ was almost similar and averaged $37.5 \mathrm{wt} \%$. For other samples, the biochar yield at $\mathrm{T}_{\mathrm{g}}=400^{\circ} \mathrm{C}$ averaged $31.2 \mathrm{wt} \%$.

For all the samples, an increase in the heating medium temperature $\left(\mathrm{T}_{\mathrm{g}}=400 \rightarrow 600{ }^{\circ} \mathrm{C}\right)$ leads to a decrease in the biochar yield by an average of $6.2 \mathrm{wt} \%\left(\mathrm{~m}_{\mathrm{b}}{ }^{600}{ }^{\circ} \mathrm{C} \approx 27.7 \mathrm{wt} \%\right.$ ). The most significant change in the biochar yield can be observed when the temperature $\mathrm{T}_{\mathrm{g}}$ rises from $400{ }^{\circ} \mathrm{C}$ to $500{ }^{\circ} \mathrm{C}$. This dependence correlates with the results of the thermal analysis presented in Figure 3. The most significant change in the biochar yield, in the considered temperature range of the heating medium, is found for the peanut and pine nut shell samples (the relative change was about $15.8 \%$ ).

A negligible change in the biochar yield could be observed as the heating medium temperature increased from $500{ }^{\circ} \mathrm{C}$ to $600{ }^{\circ} \mathrm{C}$. Thus, for the samples of almond, pistachio, 
walnut, and pine nut shells, $\mathrm{T}_{\mathrm{g}}$ increased from $500{ }^{\circ} \mathrm{C}$ to $600^{\circ} \mathrm{C}$ and changed the biochar yield by about $0.9 \%$. For the macadamia and hazelnut shell samples, the change in the biochar yield was more significant and amounted to about $3.0 \mathrm{wt} \%$.

\subsection{Analysis of Non-Condensed Gas-Phase Products}

Figure 5 shows the quantitate concentration curves for non-condensing gas-phase pyrolysis products released $\left(\mathrm{CO}, \mathrm{CO}_{2}, \mathrm{CH}_{4}, \mathrm{H}_{2}\right)$, obtained at different temperatures of the heating medium.
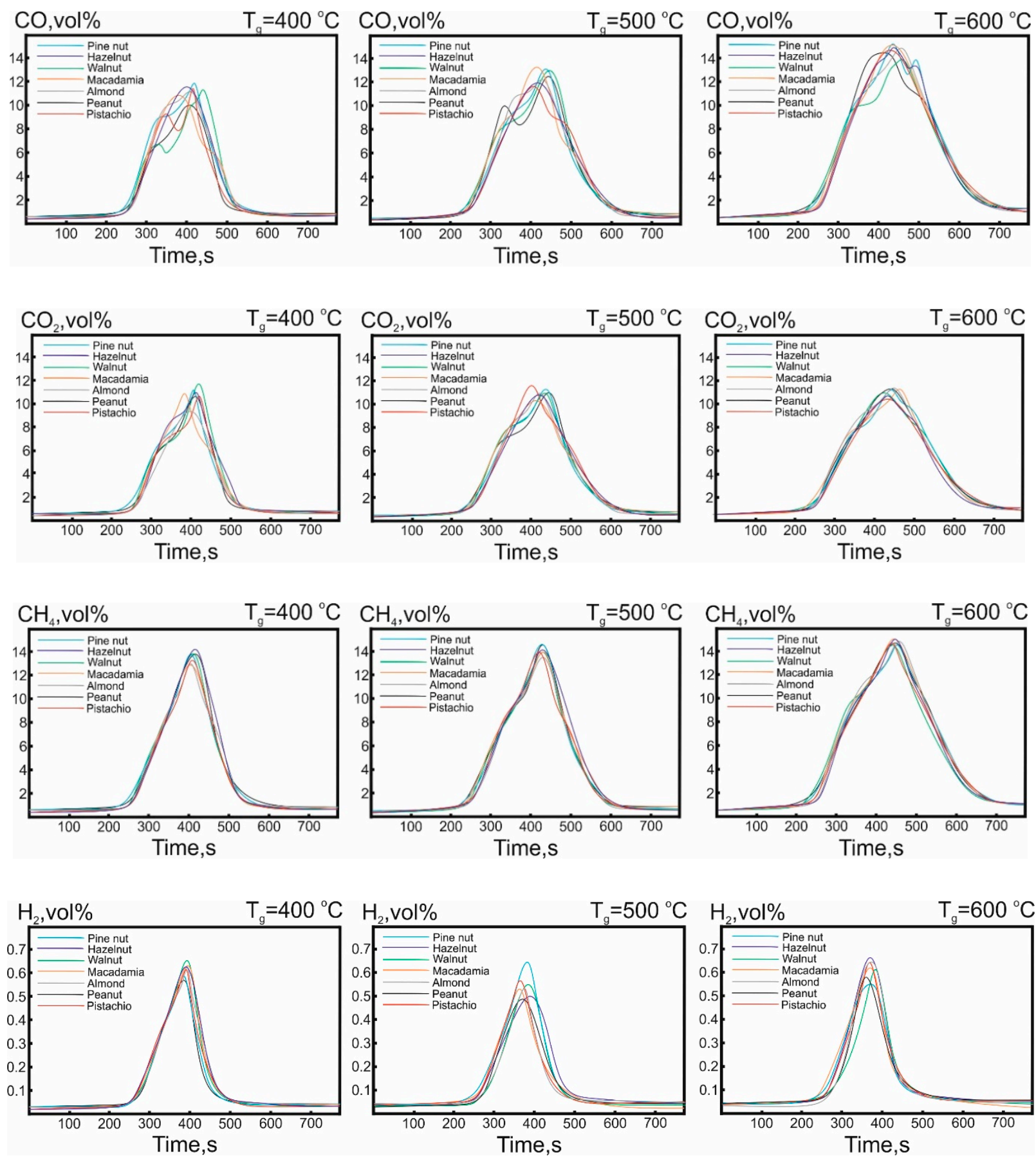

Figure 5. Concentration curves of the formed compounds $\mathrm{CO}, \mathrm{CO}_{2}, \mathrm{CH}_{4}$, and $\mathrm{H}_{2}$ in the non-condensing gas-phase products, of the pyrolysis of the nutshell, at different temperatures of the heating medium $\left(\mathrm{T}_{\mathrm{g}}=400-600{ }^{\circ} \mathrm{C}\right)$. 
The concentration curve profiles, characterizing the release of $\mathrm{CO}$ and $\mathrm{CO}_{2}$ for all studied samples, had a monomodal form with a pronounced additional shoulder for all considered temperatures of the heating medium. The average values of the concentration maximum for $\mathrm{CO}$ and $\mathrm{CO}_{2}$, for all studied samples, were $12.7 \mathrm{vol} \%$ and $10.8 \mathrm{vol} \%$, respectively. For methane, this value was equal to $14 \mathrm{vol} \%$.

Due to the same heating rate $\left(60{ }^{\circ} \mathrm{C} / \mathrm{min}\right)$, the beginning of the non-condensable gas-phase product formation was observed in typical time intervals at a temperature range $240-280{ }^{\circ} \mathrm{C}$, which correlated with the data on the results of thermal decomposition of the nutshell shown in Figure 3. The characteristic difference between the presented profiles and temperatures of the heating medium was the time interval of the releasing of noncondensing gas-phase products. At the same time, the position of the maximums related to time remained almost unchanged, which was associated with the similar temperatures of the heating medium.

Figure 5 also shows that a greater increase, in the area of the subintegral curve for the $\mathrm{CO}, \mathrm{CO}_{2}$, and $\mathrm{CH}_{4}$, was observed in the case of an increase in the temperature $\mathrm{T}_{\mathrm{g}}$ from 400 to $500{ }^{\circ} \mathrm{C}$, which correlated with the data presented in Figure 4 and may be associated with additional decomposition of lignin.

\subsection{Biochar Characteristics}

Table 3 presents the characteristics and elemental composition of the biochar samples obtained by pyrolysis of nut shells, depending on the heating medium temperature $\left(\mathrm{T}_{\mathrm{g}}=400-600^{\circ} \mathrm{C}\right)$.

Table 3. Physicochemical characteristics of the biochar samples.

\begin{tabular}{|c|c|c|c|c|c|c|c|c|c|c|}
\hline \multirow{3}{*}{ Sample } & \multicolumn{5}{|c|}{ Characteristics } & \multicolumn{5}{|c|}{ Elemental Composition * } \\
\hline & $\mathbf{W}^{\mathbf{r}}$ & $A^{d}$ & $\mathrm{~V}^{\mathrm{r}}$ & LHV & Iodine Number & $C^{d}$ & $\mathrm{H}^{\mathrm{d}}$ & $N^{d}$ & $S^{d}$ & $O^{d}$ \\
\hline & & $w t \%$ & & $\mathrm{MJ} / \mathrm{kg}$ & $\mathrm{mg} / \mathrm{g}$ & \multicolumn{5}{|c|}{ wt $\%$} \\
\hline Pine400 & 1.3 & 1.5 & 24.6 & 28.8 & 134.9 & 77.2 & 4.0 & 0.4 & - & 16.9 \\
\hline Pine500 & 1.7 & 1.8 & 18.4 & 31.1 & 181.7 & 82.9 & 3.2 & 0.4 & - & 11.7 \\
\hline Pine600 & 2.0 & 2.1 & 14.3 & 31.6 & 202.1 & 86.0 & 2.8 & 0.4 & - & 8.7 \\
\hline $\mathrm{H} 400$ & 1.8 & 2.5 & 22.8 & 29.6 & 96.3 & 75.1 & 3.9 & 0.3 & - & 18.2 \\
\hline H500 & 2.2 & 2.9 & 20.6 & 30.6 & 123.2 & 78.1 & 3.4 & 0.4 & - & 15.2 \\
\hline H600 & 1.8 & 3.5 & 13.6 & 32.7 & 150.6 & 84.3 & 2.9 & 0.3 & - & 9.0 \\
\hline W400 & 1.7 & 2.6 & 25.1 & 29.6 & 146.6 & 75.7 & 3.9 & 0.2 & - & 17.6 \\
\hline W500 & 1.6 & 3.3 & 22.2 & 31.7 & 163.3 & 80.9 & 3.4 & 0.2 & - & 12.2 \\
\hline W600 & 1.7 & 3.9 & 13.6 & 32.7 & 241.9 & 84.6 & 2.8 & 0.3 & - & 8.5 \\
\hline M400 & 1.3 & 1.5 & 27.4 & 28.7 & 85.8 & 76.8 & 3.8 & 0.4 & - & 17.5 \\
\hline M500 & 2.0 & 2.5 & 20.3 & 30.0 & 105.1 & 81.4 & 3.3 & 0.4 & - & 12.4 \\
\hline M600 & 1.6 & 2.8 & 19.5 & 32.8 & 185.4 & 89.8 & 2.4 & 0.5 & - & 4.5 \\
\hline A400 & 1.0 & 2.5 & 24.8 & 29.9 & 147.2 & 77.3 & 3.6 & 0.4 & - & 16.2 \\
\hline A500 & 1.4 & 2.7 & 18.5 & 31.2 & 179.3 & 82.2 & 2.9 & 0.3 & - & 11.9 \\
\hline A600 & 1.8 & 3.3 & 15.2 & 32.0 & 181.7 & 84.5 & 2.7 & 0.3 & - & 9.2 \\
\hline Pean 400 & 2.6 & 6.8 & 29.7 & 27.2 & 109.4 & 66.8 & 4.2 & 1.5 & - & 20.7 \\
\hline Pean500 & 2.8 & 7.2 & 23.5 & 28.3 & 164.3 & 69.0 & 3.5 & 1.5 & - & 18.8 \\
\hline Pean600 & 1.8 & 7.7 & 20.3 & 29.7 & 217.2 & 73.1 & 3.0 & 1.5 & - & 14.7 \\
\hline Pist400 & 1.1 & 3.2 & 25.1 & 29.3 & 149.3 & 76.8 & 3.5 & 0.2 & - & 16.3 \\
\hline Pist500 & 1.6 & 3.8 & 16.7 & 31.1 & 158.1 & 81.2 & 2.8 & 0.2 & - & 12.0 \\
\hline Pist600 & 1.7 & 4.6 & 12.3 & 32.1 & 192.8 & 84.9 & 2.6 & 0.2 & - & 7.7 \\
\hline
\end{tabular}

${ }^{\mathrm{r}}$-as-received basis, ${ }^{\mathrm{d}}$ - dry basis, ${ }^{*}$ - prior to the analysis, the sample was dried to constant weight at $105^{\circ} \mathrm{C}$.

An increase in the heating medium temperature $\left(\mathrm{T}_{\mathrm{g}}=400 \rightarrow 600^{\circ} \mathrm{C}\right)$ initiated a linear increase in the carbon content (average relative increase of $11.6 \%$ ) and in the lower heat value (average relative increase of $10.3 \%$ ) for virtually all the biochar samples obtained. For the samples derived from macadamia, hazelnut, and peanut shells, the relative increase in these parameters was most significant as $\mathrm{T}_{\mathrm{g}}$ increased from $500{ }^{\circ} \mathrm{C}$ to $600^{\circ} \mathrm{C}$ (on average 
by $9 \%$ ). In general, certain dependences of changes in the characteristics and elemental composition correlate with the data presented in Figure 4.

The maximum LHV value (about $32.7 \mathrm{MJ} / \mathrm{kg}$ ) was observed for the samples derived from macadamia, hazelnut, and walnut shells at the heating medium temperature of $600{ }^{\circ} \mathrm{C}$. In this case, the maximum carbon content $\left(\mathrm{C}^{\mathrm{d}}=89.8 \mathrm{wt} \%\right)$ was observed for sample M600. In turn, the minimum values of LHV (27.2-29.7 MJ $/ \mathrm{kg})$ and C (66.8-73.1 $\mathrm{wt} \%)$ were found for the biochar samples obtained from peanut shells, which is due to a high ash content $\left(\mathrm{A}^{\mathrm{d}}=6.8-7.7 \mathrm{wt} \%\right)$.

Thus, a high LHV value, absence of sulfur, low content of ash, and volatiles make biochar a promising fuel or food feedstock [26]. According to [27], a high C/N ratio facilitates immobilization of microbes in inorganic nitrogen. Therefore, this biochar has the ability to retain nutrients and can be used in the agricultural sector for growing various crops.

Figure 6 shows a Van Krevelen diagram used to compare the elemental composition of the produced biochar samples (Table 2) and a feedstock (Table 1).

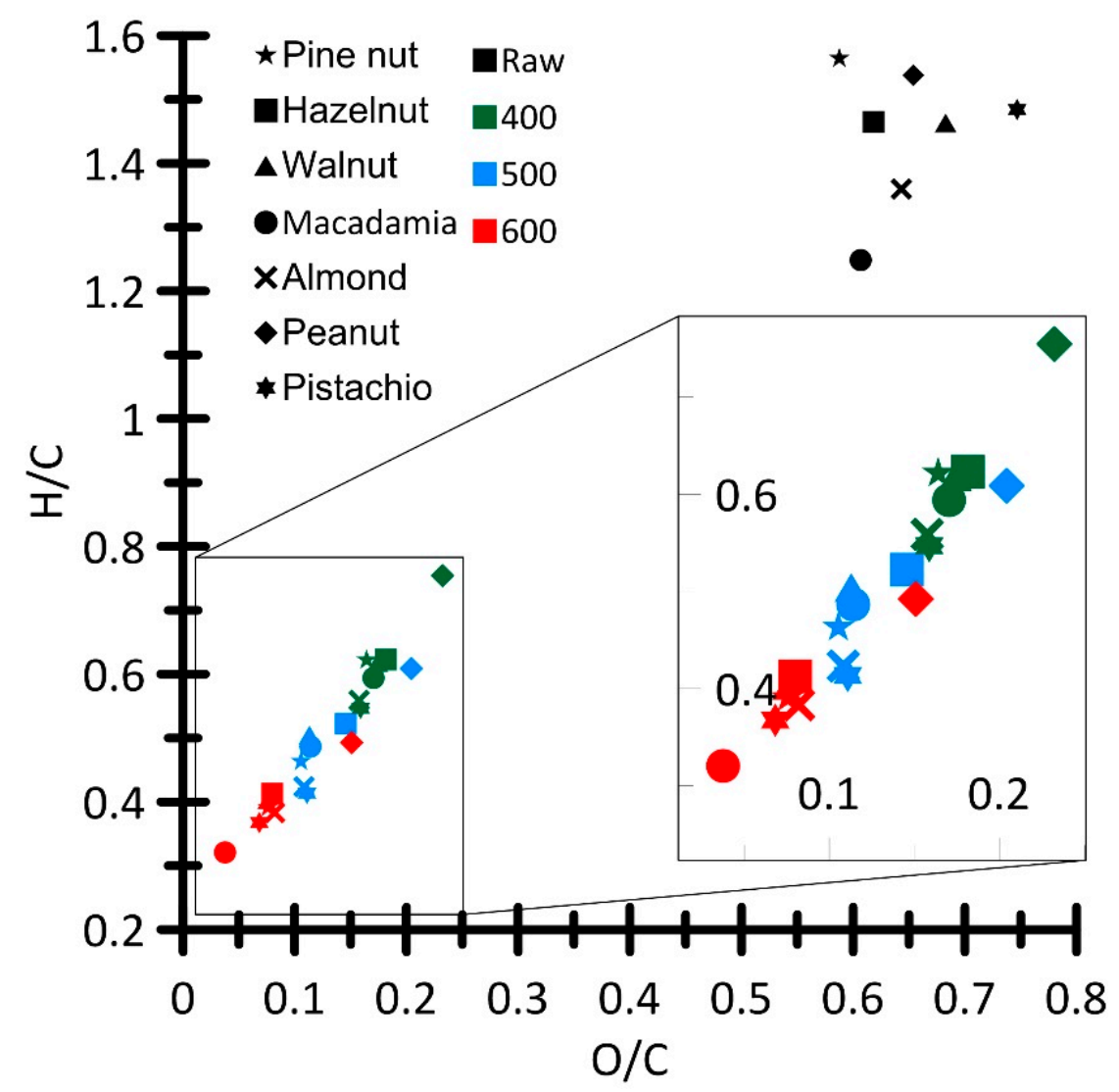

Figure 6. Van Krevelen diagram.

At increased temperature of the heating medium, the values of the $\mathrm{H} / \mathrm{C}$ and $\mathrm{O} / \mathrm{C}$ ratios decreased, due to the loss of oxygen-containing functional groups on the biochar surface and a decrease in its hydrophilicity. This is an important indicator of biochar stability [28]. According to [29], decreased H/C hydrophilicity facilitates a quantitative decrease in moisture taken from the atmosphere.

For all the samples, the iodine number was observed to increase as temperature $T_{g}$ increased, which indirectly indicates the development of the particle surface and is a relative indicator of the biochar porosity. The average iodine number, for all the samples, amounted to $158 \mathrm{mg} / \mathrm{g}$. The biochar samples, derived from macadamia and hazelnuts, showed the minimum values of the iodine number. However, macadamia biochar exhibited 
the greatest change in this parameter. Thus, at increased temperature $\mathrm{T}_{\mathrm{g}}\left(400 \rightarrow 600{ }^{\circ} \mathrm{C}\right)$, a relative increase in the iodine number attained $116 \%$ (from 85.8 to $185.4 \mathrm{mg} / \mathrm{g}$ ).

Figure 7 presents the results of scanning electron microscopy of the particles of the biochar samples.
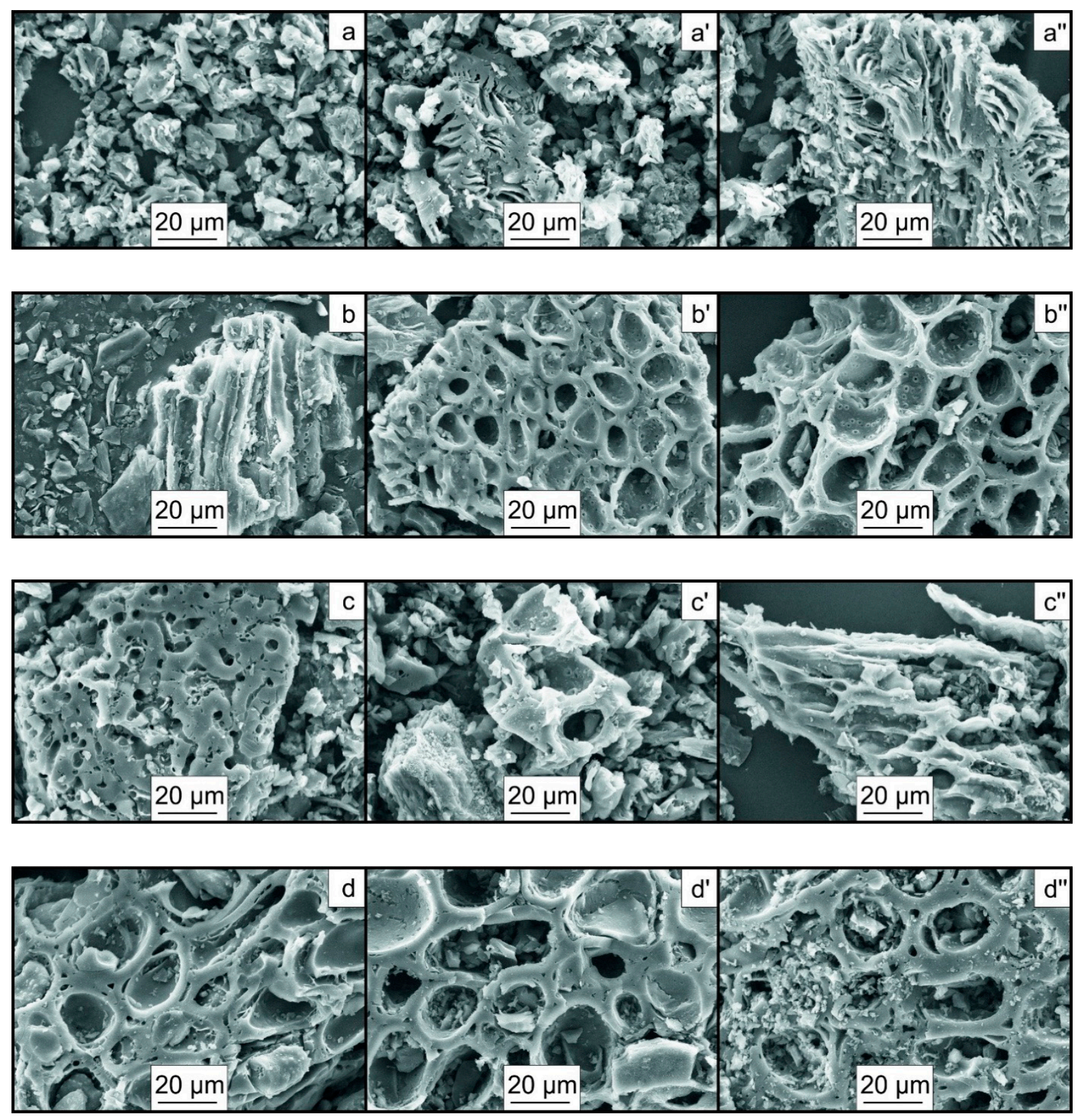

Figure 7. Cont. 

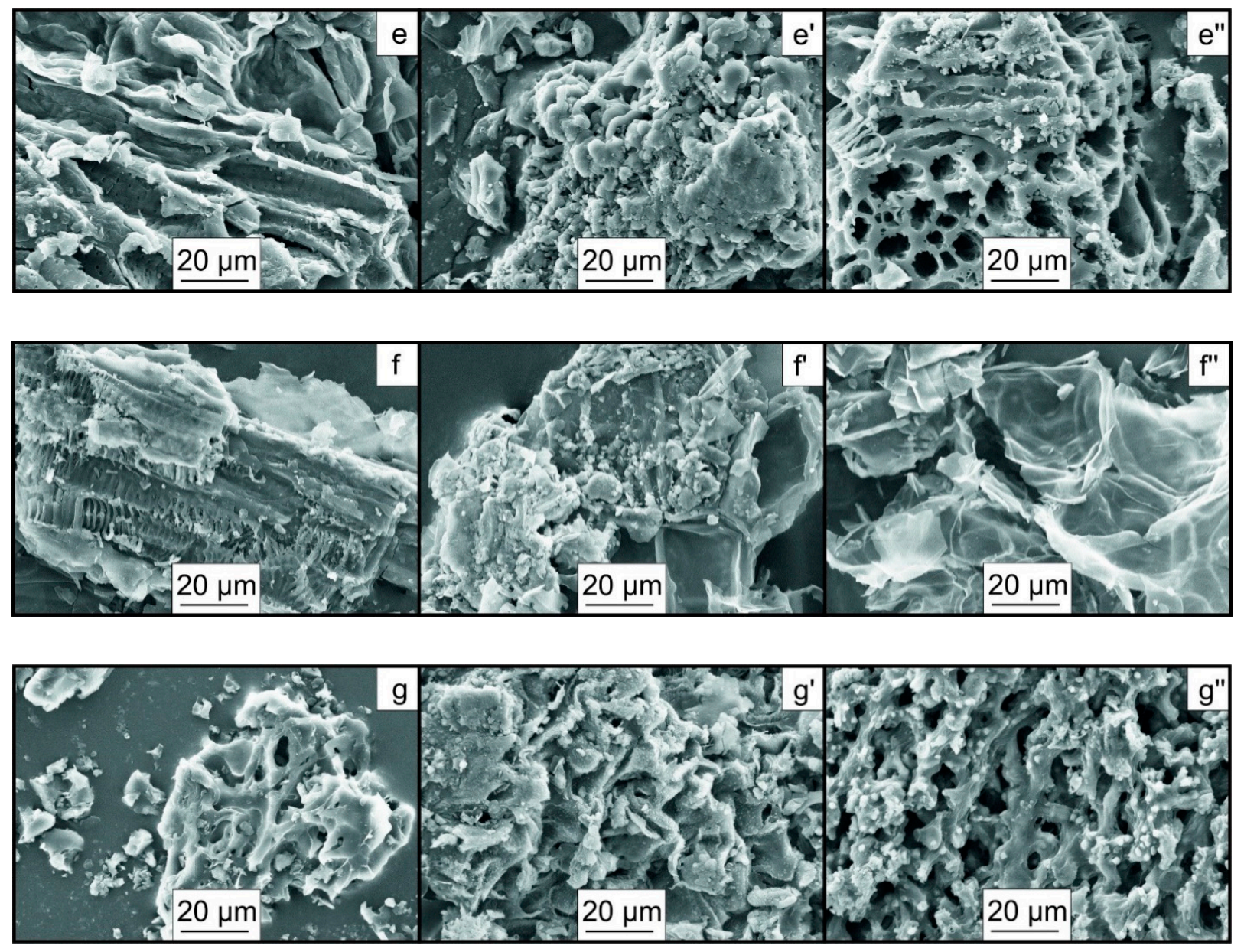

Figure 7. SEM images of the particles of the biochar samples: $\left(\mathbf{a}, \mathbf{a}^{\prime}, \mathbf{a}^{\prime \prime}\right)$-Pine400, Pine500, Pine600; $\left(\mathbf{b}, \mathbf{b}^{\prime}, \mathbf{b}^{\prime \prime}\right)$ - $\mathrm{H} 400$, H500, H600; (c, $\left.\mathbf{c}^{\prime}, \mathbf{c}^{\prime \prime}\right)$-W400, W500, W600; (d, $\left.\mathbf{d}^{\prime}, \mathbf{d}^{\prime \prime}\right)$-M400, M500, M600; (e, $\left.\mathbf{e}^{\prime}, \mathbf{e}^{\prime \prime}\right)$-A400, A500, A600; (f, $\left.\mathbf{f}^{\prime}, \mathbf{f}^{\prime \prime}\right)$-Pean400, Pean500, Pean600; $\left(\mathbf{g}, \mathbf{g}^{\prime}, \mathbf{g}^{\prime \prime}\right)$-Pist400, Pist500, Pist600 (×1000).

The pyrolysis of the nut shell biomass, at different temperatures of the heating medium, results in a dramatic change in the morphology of the particle surface in the produced biochar. This is manifested in an increased inhomogeneity of the surface structure of particles and the formation of additional depressions, pores, and channels. Temperature activation of the feedstock apparently increases the specific surface area of particles, which is evidenced by changes in the iodine number values (Table 2). In [30], an increased pyrolysis temperature was reported to increase the number of formed pores. In addition, thermal decomposition of chemical bonds, at higher temperatures, can cause melting of some compounds, which contribute to additional ruptures of bonds and a change in the structure of biochar particles, which is manifested in the formation of large pores [31]. Thus, Yuan H. et al. [32] reported that, with an increase in the pyrolysis temperature of biomass (from $300{ }^{\circ} \mathrm{C}$ to $700{ }^{\circ} \mathrm{C}$ ), an increase in the specific surface area and porosity of biochar particles from 3.78 to $8.68 \mathrm{~m}^{2} / \mathrm{g}$ and from $0.0053 \mathrm{~cm}^{3} / \mathrm{g}$ to $0.0136 \mathrm{~cm}^{3} / \mathrm{g}$ was observed, respectively. However, the value of the pore diameter remained almost unchanged. Leng L. et al. [33] reported that a significant change in textural characteristics occurred in the temperature range of $300-500{ }^{\circ} \mathrm{C}$ during the removal of hemicellulose and cellulose. A significant effect was exerted by the ash content, which led to clogging of pores during the pyrolysis of biomass [34]. The value of the specific surface area of biochar depended on the content of lignin, which has a wide temperature range of decomposition and high stability [35].

The most significant changes in the morphology of particles of the biochar samples, observed as temperature $\mathrm{T}_{\mathrm{g}}$ increased from $400{ }^{\circ} \mathrm{C}$ to $500{ }^{\circ} \mathrm{C}$, are associated with the 
complete decomposition of cellulose (Figure 3). Thus, the biochar samples derived from hazelnut, walnut, macadamia, and almond shells exhibit an increased number of rounded depressions on the surface and the formation of additional channels with a diameter of more than 1-27 $\mu \mathrm{m}$. Wang et al. [36] reported that the biochar surface can contain visible pores, which provide a high specific surface area.

Figure 8 presents the results of the thermal analysis of the biochar samples in an inert atmosphere.

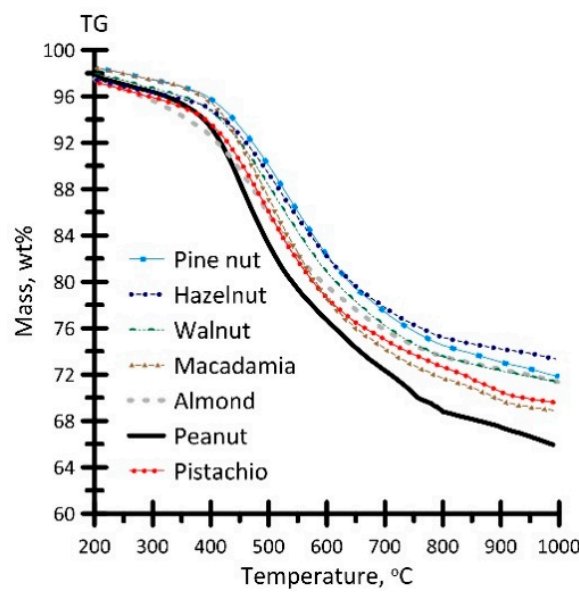

(a)

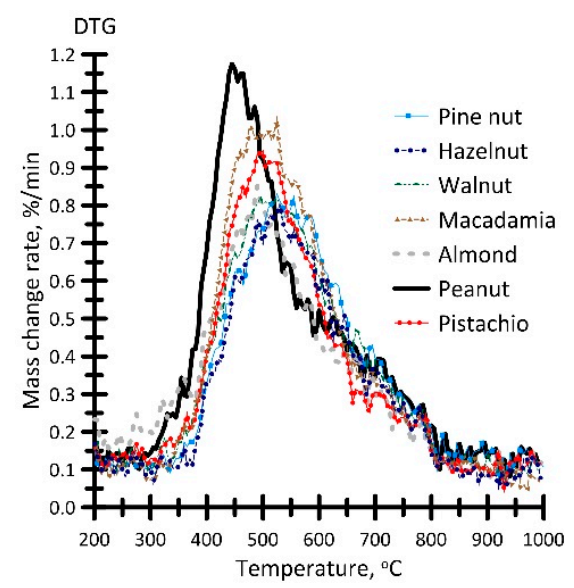

(d)

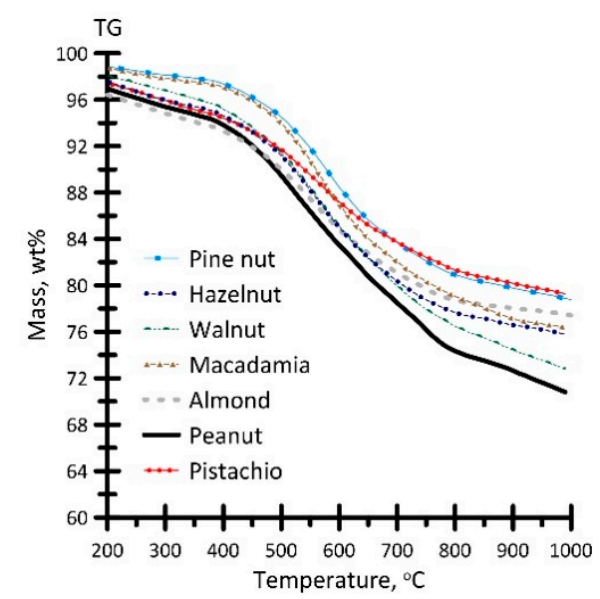

(b)

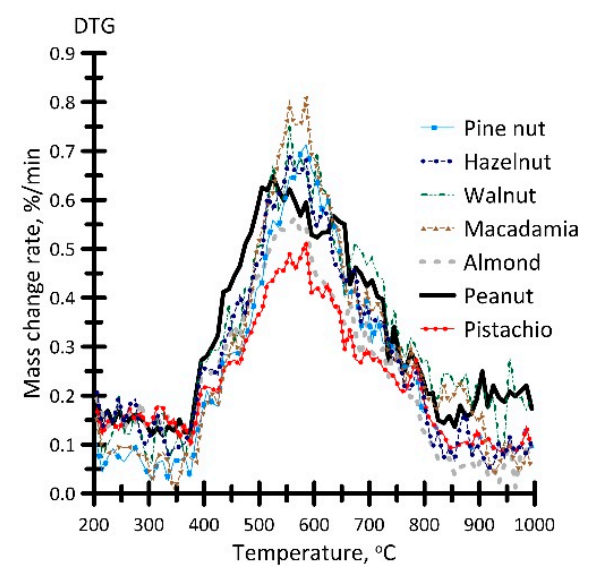

(e)

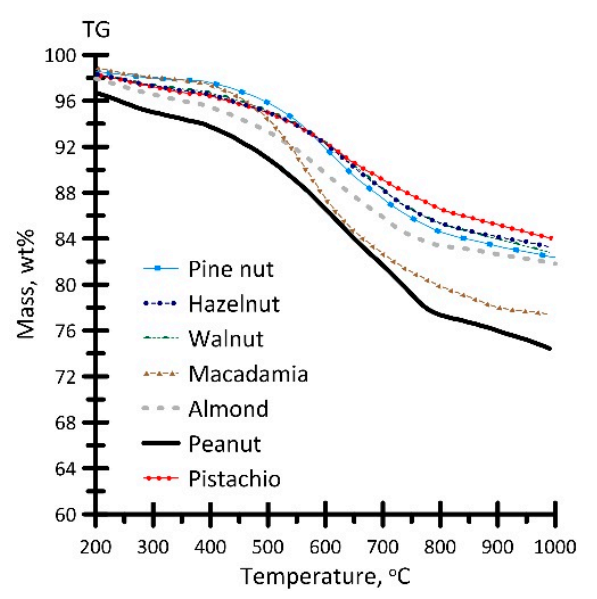

(c)

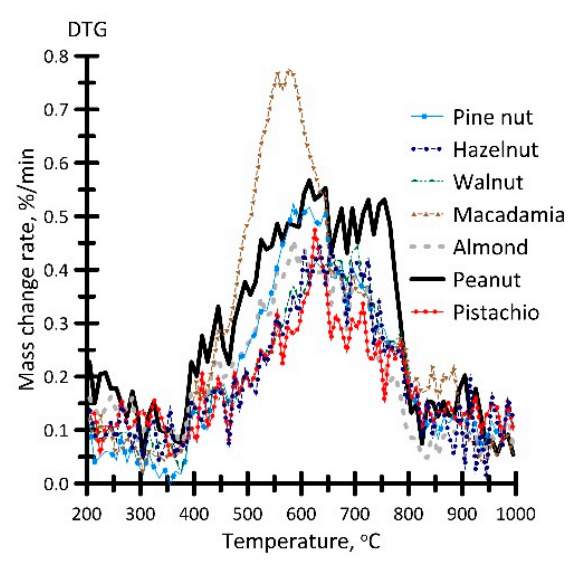

(f)

Figure 8. TG $(\mathbf{a}-\mathbf{c})$ and DTG $(\mathbf{d}-\mathbf{f})$ curves for the process of thermal decomposition of the biochar samples produced at different temperatures: $(\mathbf{a}, \mathbf{d})-400{ }^{\circ} \mathrm{C},(\mathbf{b}, \mathbf{e})-500{ }^{\circ} \mathrm{C},(\mathbf{c}, \mathbf{f})-600^{\circ} \mathrm{C}$. Argon flow rate $-150 \mathrm{~mL} / \mathrm{min}$, heating rate $-10{ }^{\circ} \mathrm{C} / \mathrm{min}$, sample weight $\approx 15 \mathrm{mg}$.

Comparison of the obtained results shows that the TG profiles (Figure 8a-c) of thermal decomposition of the biochar samples, produced via pyrolysis at different temperatures, exhibit significant differences. This is manifested in the shift of the initial temperature of thermal decomposition $\mathrm{T}_{\mathrm{d}}$ by $40-110{ }^{\circ} \mathrm{C}$ (depending on the pyrolysis temperature). The change in the parameter $\mathrm{T}_{\mathrm{d}}$, which is determined in the temperature range of $390-500{ }^{\circ} \mathrm{C}$, has a direct correlation with the content of volatile compounds in the samples (Table 2). The total weight loss of biochar attains 10.5-31.2 $\mathrm{wt} \%$, which is in reasonably good agreement with the content of external moisture and volatile compounds in the samples (Table 2).

Figure $8 \mathrm{~d}-\mathrm{f}$ shows that the DTG profiles are monomodal in shape in the temperature range of $350-800{ }^{\circ} \mathrm{C}$, which corresponds to cellulose decomposition (for the biochar samples produced at $\mathrm{T}_{\mathrm{g}}=400{ }^{\circ} \mathrm{C}$ (Figure 8d)) and lignin. It should be noted that the thermal 
conversion rate $\mathrm{w}_{\max }$ is observed to reduce as the degree of coalification increases. As a result, the process shifts to the high-temperature region. Figure $8 d-f$ shows an insignificant expansion, of the temperature ranges for the DTG profiles, at decreased parameter $\mathrm{w}_{\max }$.

Despite the linear decrease in the content of volatile compounds at increased pyrolysis temperature (Table 2), the intensity of the change in the parameter $\mathrm{w}_{\max }$ in the biochar samples, obtained at temperatures $\mathrm{T}_{\mathrm{g}}=500$ and $600{ }^{\circ} \mathrm{C}$, is observed to decrease (Figure 8e-f).

Figure 9 presents the results of the thermal analysis of the biochar samples in an oxidizing atmosphere.

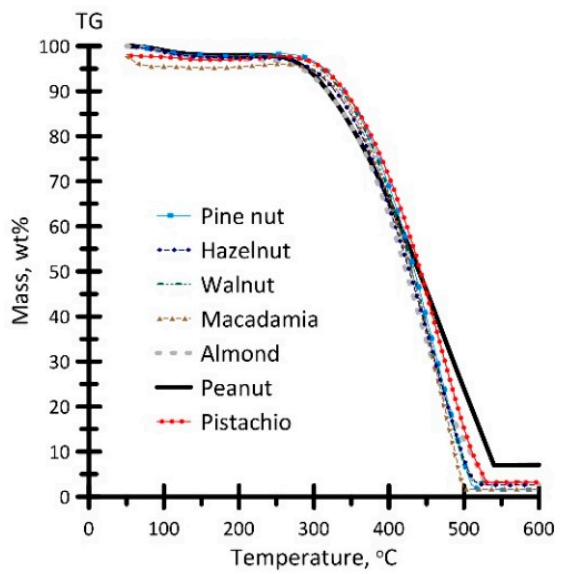

(a)

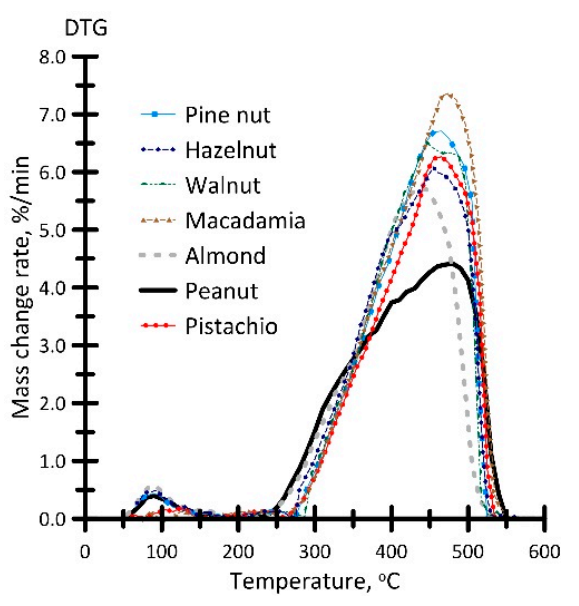

(d)

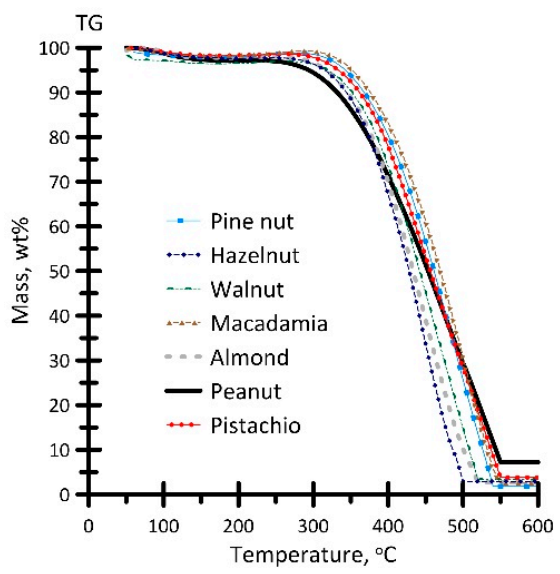

(b)

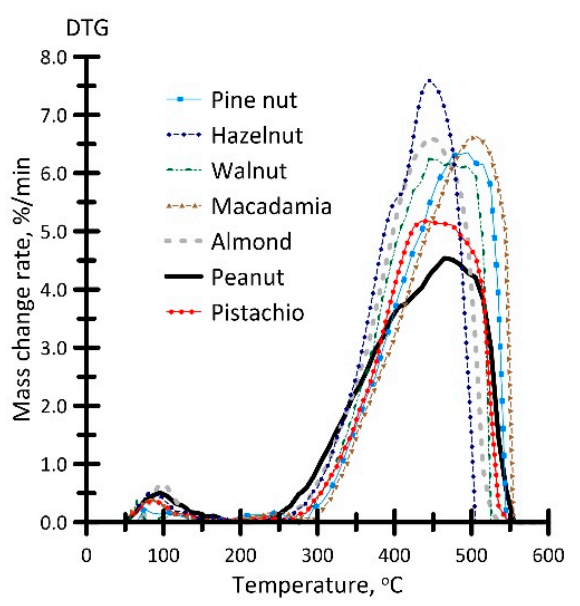

(e)

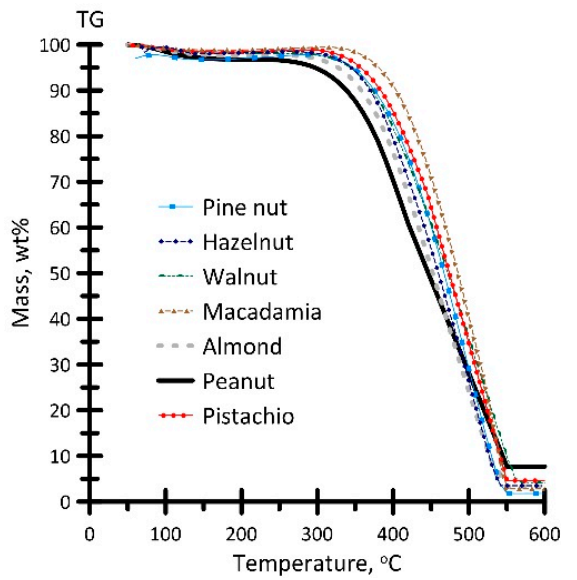

(c)

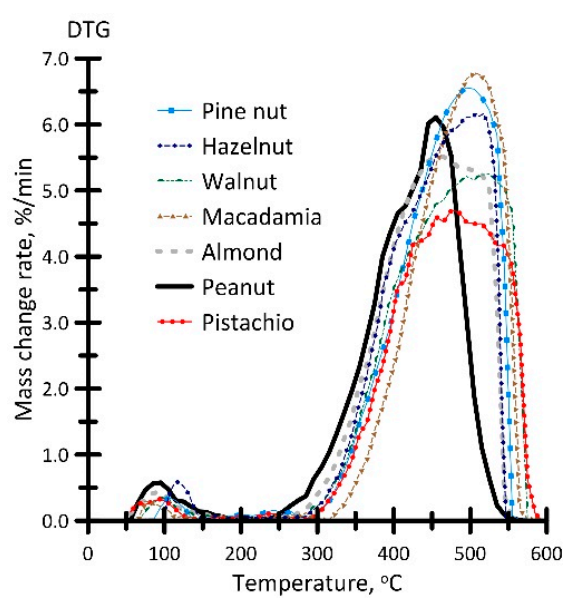

(f)

Figure 9. TG $(\mathbf{a}-\mathbf{c})$ and DTG $(\mathbf{d}-\mathbf{f})$ profiles for the oxidation process of the biochar samples produced at different temperatures: $(\mathbf{a}, \mathbf{d})-400{ }^{\circ} \mathrm{C} ;(\mathbf{b}, \mathbf{e})-500{ }^{\circ} \mathrm{C} ;(\mathbf{c}, \mathbf{f})-600^{\circ} \mathrm{C}$. Air flow rate $-150 \mathrm{~mL} / \mathrm{min}$, heating rate $-10^{\circ} \mathrm{C} / \mathrm{min}$, sample weight $\approx 15 \mathrm{mg}$.

Comparison of the obtained results shows that the TG profiles (Figure $9 \mathrm{a}-\mathrm{c}$ ) of the oxidation process differ significantly, which is due to the carbon content in the biochar samples (Table 2). Thus, the degree of coalification increases, and the content of volatile compounds decreases, as the initial temperatures $T_{i}$ and the final temperature $T_{f}$ of intense oxidation grow (on average by $73{ }^{\circ} \mathrm{C}$ and $48{ }^{\circ} \mathrm{C}$, respectively). As a result, the oxidation process shifts to the high-temperature region. In this case, the temperature shift $\mathrm{T}_{\max }$ that corresponds to the maximum reaction rate $\mathrm{w}_{\max }$ attained $62{ }^{\circ} \mathrm{C}$. It should be noted that oxidation of all the biochar samples occurs at temperatures $\mathrm{T}_{\mathrm{i}}$ and $\mathrm{T}_{\mathrm{f}}$, ranging from $309{ }^{\circ} \mathrm{C}$ to $382{ }^{\circ} \mathrm{C}$ and from $512{ }^{\circ} \mathrm{C}$ to $560{ }^{\circ} \mathrm{C}$, respectively. 
For the samples, the change in the TG profiles of the oxidation process affects the shape of the DTG profiles (Figure 9d-f). The analysis of these profiles reveals three stages of the change in the sample weight. At the first stage, the physically adsorbed moisture evaporates (up to $110^{\circ} \mathrm{C}$ ). At the second stage, thermal destruction of biochar particles is accompanied by the sublimation of residual volatile compounds (at $280-410{ }^{\circ} \mathrm{C}$ ) after pyrolysis of the nut shells at different temperatures. At the third stage, active oxidation of the resulting carbon residue occurs at $380-580{ }^{\circ} \mathrm{C}$. In this case, specific temperature regions cannot be determined, since the sublimation of volatile compounds and the oxidation of the resulting carbon occurs in parallel. This can be due to a lower content of volatile compounds on the surface of the biochar particles and its more developed morphological structure that exhibits more residue expanded cracks and pores (Figure 7).

Comparison of the oxidation parameters (Figure 9) of the biochar samples reveals a direct correlation between the oxygen content (oxygen-containing functional groups) and the fuel reactivity, which is manifested in a changed initial temperature of intense oxidation $\mathrm{T}_{\mathrm{i}}$. Thus, the biochar samples derived from peanut shells (Pean400-600) exhibit the highest reactivity $\left(\mathrm{T}_{\mathrm{i}}=309-323^{\circ} \mathrm{C}\right.$, depending on the heating medium temperature). In this case, the samples are characterized by the highest final temperature of intense oxidation $\mathrm{T}_{\mathrm{f}}$ $\left(547-560^{\circ} \mathrm{C}\right)$, which can be due to a high ash content (Table 2$)$.

\subsection{Kinetic Analysis of the Biochar Thermal Conversion}

Table 4 presents the activation energy values determined via the Coats-Redfern method using thermal analysis data for biochar samples obtained by pyrolysis at different temperatures.

Table 4. Activation energy of biochar conversion in inert and oxidative medium $\mathrm{E}_{\mathrm{a}}, \mathrm{kJ} / \mathrm{mol}$.

\begin{tabular}{ccccccc}
\hline & \multicolumn{3}{c}{ Inert Medium } \\
\cline { 2 - 6 } Sample & \multicolumn{5}{c}{ Oxidative Medium } \\
\cline { 2 - 7 } & $\mathbf{4 0 0}$ & $\mathbf{5 0 0}$ & $\mathbf{6 0 0}$ & $\mathbf{4 0 0}$ & $\mathbf{5 0 0}$ & $\mathbf{6 0 0}$ \\
\cline { 2 - 6 } Pine nut & 29.0 & 34.1 & 35.0 & 67.6 & 74.2 & 78.8 \\
Hazelnut & 28.6 & 27.5 & 34.8 & 67.5 & 78.8 & 70.3 \\
Walnut & 23.6 & 25.4 & 26.2 & 49.0 & 72.3 & 75.6 \\
Macadamia & 29.9 & 32.8 & 34.8 & 70.9 & 73.4 & 91.0 \\
Almond & 19.4 & 22.0 & 25.1 & 60.6 & 74.1 & 70.2 \\
Peanut & 21.1 & 22.1 & 23.3 & 49.1 & 54.1 & 69.7 \\
Pistachio & 13.5 & 14.7 & 17.6 & 66.9 & 72.7 & 80.8 \\
\hline
\end{tabular}

It could be seen that, with an increase in the pyrolysis temperature, the activation energy had been increasing, which was in correlation with the change in volatile compounds content in the studied samples (Table 3). This was the case of the shift of TG profiles to a higher temperature region (Figures 8 and 9). Differences in the activation energy values for conversion processes in an inert and oxidizing mediums were associated with incomplete decomposition of the sample in an inert environment during pyrolysis. Generally, the activation energy values for biochar conversion in both inert and oxidative mediums had been increasing with temperature of biochar obtaining. It may be caused by more complete conversion of biochar during raw material pyrolysis at higher temperature. The highest reactivity in an inert medium was observed for pistachio biochar sample, and in an oxidative medium - for walnut and peanut biochar samples. The highest activation energy values were almost on par with several other samples, thus making the clear choice of a biochar sample with lowest reactivity almost impossible.

Activation energy values, obtained for the conversion of the biochar samples in an inert medium, were varied in range 10-35 kJ/mol, which were much smaller than usually reported values for the decomposition of main components of the nut shells100-350 kJ/mol [9,37-40]. Close values were reported in [3,8] for lignin fiber decomposition in ranges 38-42 and 19-45 kJ/mol, respectively. Thus the mass loss observed during TG 
experiments in inert medium could be caused by slow lignin fiber decomposition. Such values could also indicate the prevailing of lignin into composition of obtained biochar.

Characteristic activation energy values for oxidation of all studied biochar samples were varied within $50-80 \mathrm{~kJ} / \mathrm{mol}$ range (with several exceptions). For biochar samples obtained at $400{ }^{\circ} \mathrm{C}$, this range was lower- $50-70 \mathrm{~kJ} / \mathrm{mol}$-while for biochar samples, obtained at $500{ }^{\circ} \mathrm{C}$ and $600{ }^{\circ} \mathrm{C}$ this range was higher-around $70-80 \mathrm{~kJ} / \mathrm{mol}$ with $500{ }^{\circ} \mathrm{C}$ peanut and $600{ }^{\circ} \mathrm{C}$ macadamia shell biochar as exceptions. Obtained values were close to those of pine nut shell biochar reported in [13] which were $60-63 \mathrm{~kJ} / \mathrm{mol}$. These values were characteristic for the lignin oxidation reported in [3], additionally proving lignin-dominated nature of biochars obtained.

\section{Conclusions}

The process of slow pyrolysis of nut shells was experimentally studied at various temperatures $\left(T_{g}=400-600^{\circ} \mathrm{C}\right.$, step of $\left.100^{\circ} \mathrm{C}\right)$ in a nitrogen-purged atmosphere $(\mathrm{G}=2 \mathrm{~L} / \mathrm{min})$. The feedstock was heated, indirectly, at a rate of $60^{\circ} \mathrm{C} / \mathrm{min}$ using a double-walled reactor.

The nut shell samples had similar characteristics and elemental composition. Thermal analysis, performed in an argon atmosphere, revealed a significant weight loss $(\Delta \mathrm{m}=32.8-43.0 \mathrm{wt} \%)$ in the temperature range of $290-400^{\circ} \mathrm{C}$, due to cellulose decomposition.

The amount of the resulting carbon residue (on average, from $33.9 \mathrm{wt} \%$ to $27.7 \mathrm{wt} \%$ ) was observed to decrease as the heating medium temperature grew up, which indicates a linear dependence (except for the pine nut shell sample).

The pyrolysis process proceeded in an exothermic regime due to the release of volatile compounds. In non-condensable gas-phase pyrolysis products, the content of $\mathrm{H}_{2}(0.7 \mathrm{vol} \%), \mathrm{CH}_{4}(14.0 \mathrm{vol} \%)$, and $\mathrm{CO}(12.7 \mathrm{vol} \%)$ was found at different time periods of the pyrolysis process.

For the produced biochar samples, the increased temperature of the heating medium increased the degree of coalification (on average from $75.1 \mathrm{wt} \%$ to $83.9 \mathrm{wt} \%$ ), the heat value (on average from $29.0 \mathrm{MJ} / \mathrm{kg}$ to $31.9 \mathrm{MJ} / \mathrm{kg}$ ) and the iodine number (on average, from $124.2 \mathrm{mg} / \mathrm{g}$ to $196.0 \mathrm{mg} / \mathrm{g}$ ). In this case, the most significant change in the particle morphology was observed for the samples obtained at $\mathrm{T}_{\mathrm{g}}=500^{\circ} \mathrm{C}$, which was manifested in the formation of a more inhomogeneous particle surface and the formation of additional cavities, pores, and channels

In addition, an increased degree of coalification and a decreased content of volatile compounds in the biochar samples led to a decrease in their reactivity, which was manifested in the growth of the initial temperature of intense oxidation by $73^{\circ} \mathrm{C}$.

Kinetic analysis of obtained biochar samples conversion revealed that for all samples the activation energy values were varied in quite narrow range- $10-35 \mathrm{~kJ} / \mathrm{mol}$ and $50-80 \mathrm{~kJ} / \mathrm{mol}$ in inert and oxidative mediums, respectively. These values were characteristic for lignin decomposition, according to literature data. The higher temperature of biochar obtained resulted in higher activation energy of its conversion in an inert and oxidative medium. It may be due to more complete removal of highly reactive components during raw material pyrolysis at high temperature.

The results obtained revealed that, despite different origins of the nut shell samples, the biochar samples, obtained via nitrogen pyrolysis at different temperatures, were characterized by similar $\mathrm{H} / \mathrm{C}$ to $\mathrm{O} / \mathrm{C}$ ratios meaning that they lay on the same line at the Van Krevelen diagram. Increasing the pyrolysis temperature resulted in a shift of corresponding point to the area of lower $\mathrm{O} / \mathrm{C}$ values. The activation energy values for conversion of obtained biochar samples, in inert and oxidative mediums, were quite similar for different nut shells, and they had been increasing with pyrolysis temperature. This provided a good background to the unification of the nut shell processing, via slow pyrolysis, for producing biochar with stable characteristics using different feedstocks 
Author Contributions: Conceptualization, K.L.; methodology, A.G., N.B., R.T. and A.K.; formal analysis, K.S.; writing-original draft preparation, K.L., K.S. and S.Y.; writing-review and editing, K.L. and K.S.; visualization, A.K.; project administration, K.L.; funding acquisition, K.L. All authors have read and agreed to the published version of the manuscript.

Funding: This work was supported by Ministry of Science and Higher Education of Russian Federation in part of the additional contract \# 075-03-2021-138/3 on subsidy from federal budget for financial support of governmental task realization for governmental services (internal number 075$\mathrm{GZ} / \mathrm{X} 4141 / 687 / 3)$.

Acknowledgments: Authors express gratitude to the TPU development program.

Conflicts of Interest: The authors declare no conflict of interest.

\section{References}

1. Zhou, X.-L.; Zhang, H.; Shao, L.-M.; Lü, F.; He, P.-J. Preparation and Application of Hierarchical Porous Carbon Materials from Waste and Biomass: A Review. Waste Biomass Valorization 2021, 12, 1699-1724. [CrossRef]

2. Mohan, D.; Pittman, C.U.; Steele, P.H. Pyrolysis of Wood/Biomass for Bio-oil: A Critical Review. Energy Fuels 2006, 20, 848-889. [CrossRef]

3. Vitoussia, T.; Brillard, A.; Kehrli, D.; Kemajou, A.; Njeugna, E.; Brilhac, J.-F. Thermogravimetric analyses and kinetic modeling of pellets built with three Cameroonian biomass. Biomass Convers. Biorefinery 2021, 11, 2107-2121. [CrossRef]

4. Liu, L.; Dai, Y. Strong adsorption of metolachlor by biochar prepared from walnut shells in water. Environ. Sci. Pollut. Res. 2021, 28, 48379-48391. [CrossRef] [PubMed]

5. Quesada, H.B.; de Araújo, T.P.; Cusioli, L.F.; de Barros, M.A.S.D.; Gomes, R.G.; Bergamasco, R. Evaluation of novel activated carbons from chichá-do-cerrado (Sterculia striata St. Hil. et Naud) fruit shells on metformin adsorption and treatment of a synthetic mixture. J. Environ. Chem. Eng. 2021, 9, 104914. [CrossRef]

6. Wu, Y.; Sun, Y.; Liang, K.; Yang, Z.; Tu, R.; Fan, X.; Cheng, S.; Yu, H.; Jiang, E.; Xu, X. Enhancing Hydrodeoxygenation of Bio-oil via Bimetallic Ni-V Catalysts Modified by Cross-Surface Migrated-Carbon from Biochar. ACS Appl. Mater. Interfaces 2021, 13, 21482-21498. [CrossRef]

7. Pepè Sciarria, T.; de Oliveira, M.A.C.; Mecheri, B.; D’Epifanio, A.; Goldfarb, J.L.; Adani, F. Metal-free activated biochar as an oxygen reduction reaction catalyst in single chamber microbial fuel cells. J. Power Sources 2020, 462, 228183. [CrossRef]

8. Noszczyk, T.; Dyjakon, A.; Koziel, J.A. Kinetic Parameters of Nut Shells Pyrolysis. Energies 2021, 14, 682. [CrossRef]

9. Kim, Y.-M.; Han, T.U.; Hwang, B.; Lee, B.; Lee, H.W.; Park, Y.-K.; Kim, S. Pyrolysis kinetics and product properties of softwoods, hardwoods, and the nut shell of softwood. Korean J. Chem. Eng. 2016, 33, 2350-2358. [CrossRef]

10. Malika, A.; Jacques, N.; Jaafar, E.F.; Fatima, B.; Mohammed, A. Pyrolysis investigation of food wastes by TG-MS-DSC technique. Biomass Convers. Biorefinery 2016, 6, 161-172. [CrossRef]

11. Xavier, T.P.; Lira, T.S.; Schettino, M.A., Jr.; Barrozo, M.A.S. A Study of pyrolysis of macadamia nut shell: Parametric sensitivity analysis of the ipr model. Braz. J. Chem. Eng. 2016, 33, 115-122. [CrossRef]

12. Qin, L.; Shao, Y.; Hou, Z.; Jiang, E. Effect of temperature on the physicochemical characteristics of pine nut shell pyrolysis products in a screw reactor. Energy Sources Part A Recover. Util. Environ. Eff. 2020, 42, 2831-2843. [CrossRef]

13. Qin, L.; Wu, Y.; Hou, Z.; Jiang, E. Influence of biomass components, temperature and pressure on the pyrolysis behavior and biochar properties of pine nut shells. Bioresour. Technol. 2020, 313, 123682. [CrossRef] [PubMed]

14. Ortiz, L.R.; Torres, E.; Zalazar, D.; Zhang, H.; Rodriguez, R.; Mazza, G. Influence of pyrolysis temperature and bio-waste composition on biochar characteristics. Renew. Energy 2020, 155, 837-847. [CrossRef]

15. Garg, D.; Kumar, S.; Sharma, K.; Majumder, C.B. Application of waste peanut shells to form activated carbon and its utilization for the removal of Acid Yellow 36 from wastewater. Groundw. Sustain. Dev. 2019, 8, 512-519. [CrossRef]

16. Duwiejuah, A.B.; Cobbina, S.J.; Quainoo, A.K.; Abubakari, A.H.; Bakobie, N. Adsorption of Potentially Toxic Metals from Mono and Multi-Metal Systems Using Groundnut and Shea Nut Shell Biochars. J. Health Pollut. 2018, 8, 180607. [CrossRef]

17. Williams, P.T.; Besler, S. The influence of temperature and heating rate on the slow pyrolysis of biomass. Renew. Energy 1996, 7 , 233-250. [CrossRef]

18. Jahirul, M.; Rasul, M.; Chowdhury, A.; Ashwath, N. Biofuels Production through Biomass Pyrolysis-A Technological Review. Energies 2012, 5, 4952-5001. [CrossRef]

19. Vamvuka, D.; Kakaras, E.; Kastanaki, E.; Grammelis, P. Pyrolysis characteristics and kinetics of biomass residuals mixtures with lignite. Fuel 2003, 82, 1949-1960. [CrossRef]

20. Sathe, P.S.; Adivarekar, R.V.; Pandit, A.B. Valorization of peanut shell biochar for soil amendment. J. Plant Nutr. 2021, 1-19. [CrossRef]

21. Ahlström, J.M.; Alamia, A.; Larsson, A.; Breitholtz, C.; Harvey, S.; Thunman, H. Bark as feedstock for dual fluidized bed gasifiers-Operability, efficiency, and economics. Int. J. Energy Res. 2019, 43, 1171-1190. [CrossRef]

22. Association, W.N. Heating Value of Various Fuels. Available online: https://world-nuclear.org/information-library/facts-andfigures/heat-values-of-various-fuels.aspx (accessed on 13 November 2021). 
23. Sarkar, J.K.; Wang, Q. Different Pyrolysis Process Conditions of South Asian Waste Coconut Shell and Characterization of Gas, Bio-Char, and Bio-Oil. Energies 2020, 13, 1970. [CrossRef]

24. Kan, T.; Strezov, V.; Evans, T.J. Lignocellulosic biomass pyrolysis: A review of product properties and effects of pyrolysis parameters. Renew. Sustain. Energy Rev. 2016, 57, 1126-1140. [CrossRef]

25. Moreira, K.C.C.S.R.; Xavier, T.P.; Araújo, J.C.S.; Santos, K.G.; Lira, T.S. Thermokinetic study of macadamia carpel pyrolysis using thermogravimetric analysis. Can. J. Chem. Eng. 2021, 24188. [CrossRef]

26. Vicente, E.D.; Vicente, A.; Evtyugina, M.; Carvalho, R.; Tarelho, L.A.C.; Oduber, F.I.; Alves, C. Particulate and gaseous emissions from charcoal combustion in barbecue grills. Fuel Process. Technol. 2018, 176, 296-306. [CrossRef]

27. Singh, B.; Singh, B.P.; Cowie, A.L. Characterisation and evaluation of biochars for their application as a soil amendment. Soil Res. 2010, 48, 516. [CrossRef]

28. Crombie, K.; Mašek, O.; Sohi, S.P.; Brownsort, P.; Cross, A. The effect of pyrolysis conditions on biochar stability as determined by three methods. GCB Bioenergy 2013, 5, 122-131. [CrossRef]

29. He, C.; Giannis, A.; Wang, J.-Y. Conversion of sewage sludge to clean solid fuel using hydrothermal carbonization: Hydrochar fuel characteristics and combustion behavior. Appl. Energy 2013, 111, 257-266. [CrossRef]

30. Suman, S.; Panwar, D.S.; Gautam, S. Surface morphology properties of biochars obtained from different biomass waste. Energy Sources Part A Recover. Util. Environ. Eff. 2017, 39, 1007-1012. [CrossRef]

31. Fu, P.; Hu, S.; Xinag, J.; Sun, L.; Yang, T.; Zhang, A.; Wang, Y.; Chen, G. Effects of Pyrolysis Temperature on Characteristics of Porosity in Biomass Chars. In Proceedings of the 2009 International Conference on Energy and Environment Technology, Guilin, China, 16-18 October 2009; pp. 109-112.

32. Yuan, H.; Lu, T.; Wang, Y.; Huang, H.; Chen, Y. Influence of pyrolysis temperature and holding time on properties of biochar derived from medicinal herb (radix isatidis) residue and its effect on soil $\mathrm{CO}_{2}$ emission. J. Anal. Appl. Pyrolysis 2014, 110, 277-284. [CrossRef]

33. Leng, L.; Xiong, Q.; Yang, L.; Li, H.; Zhou, Y.; Zhang, W.; Jiang, S.; Li, H.; Huang, H. An overview on engineering the surface area and porosity of biochar. Sci. Total Environ. 2021, 763, 144204. [CrossRef] [PubMed]

34. Sun, K.; Kang, M.; Zhang, Z.; Jin, J.; Wang, Z.; Pan, Z.; Xu, D.; Wu, F.; Xing, B. Impact of Deashing Treatment on Biochar Structural Properties and Potential Sorption Mechanisms of Phenanthrene. Environ. Sci. Technol. 2013, 47, 11473-11481. [CrossRef]

35. Sun, Y.; Yu, I.K.M.; Tsang, D.C.W.; Fan, J.; Clark, J.H.; Luo, G.; Zhang, S.; Khan, E.; Graham, N.J.D. Tailored design of graphitic biochar for high-efficiency and chemical-free microwave-assisted removal of refractory organic contaminants. Chem. Eng. J. 2020, 398, 125505. [CrossRef]

36. Wang, S.; Jiang, D.; Cao, B.; Qian, L.; Hu, Y.; Liu, L.; Yuan, C.; Abomohra, A.E.-F.; He, Z.; Wang, Q.; et al. Bio-char and bio-oil characteristics produced from the interaction of Enteromorpha clathrate volatiles and rice husk bio-char during co-pyrolysis in a sectional pyrolysis furnace: A complementary study. J. Anal. Appl. Pyrolysis 2018, 135, 219-230. [CrossRef]

37. Da Silva, J.C.G.; de Albuquerque, J.G.; Galdino, W.; de Sena, R.F.; Andersen, S.L.F. Single-step and multi-step thermokinetic study-Deconvolution method as a simple pathway for describe properly the biomass pyrolysis for energy conversion. Energy Convers. Manag. 2020, 209, 112653. [CrossRef]

38. Bhavanam, A.; Sastry, R.C. Kinetic study of solid waste pyrolysis using distributed activation energy model. Bioresour. Technol. 2015, 178, 126-131. [CrossRef]

39. Ko, K.-H.; Rawal, A.; Sahajwalla, V. Analysis of thermal degradation kinetics and carbon structure changes of co-pyrolysis between macadamia nut shell and PET using thermogravimetric analysis and 13C solid state nuclear magnetic resonance. Energy Convers. Manag. 2014, 86, 154-164. [CrossRef]

40. Kim, Y.-M.; Kim, S.; Han, T.U.; Park, Y.-K.; Watanabe, C. Pyrolysis reaction characteristics of Korean pine (Pinus Koraiensis) nut shell. J. Anal. Appl. Pyrolysis 2014, 110, 435-441. [CrossRef] 